\title{
Tropospheric BrO column densities in the Arctic derived from satellite: retrieval and comparison to ground-based measurements
}

\author{
H. Sihler ${ }^{1,2}$, U. Platt ${ }^{2}$, S. Beirle ${ }^{1}$, T. Marbach ${ }^{3}$, S. Kühl ${ }^{1}$, S. Dörner ${ }^{1}$, J. Verschaeve ${ }^{4}$, U. Frieß ${ }^{2}$, D. Pöhler ${ }^{2}$, L. Vogel $^{2}$, \\ R. Sander ${ }^{1}$, and T. Wagner ${ }^{1}$ \\ ${ }^{1}$ Max Planck Institute for Chemistry, Hahn-Meitner-Weg 1, 55128 Mainz, Germany \\ ${ }^{2}$ Institute of Environmental Physics, University of Heidelberg, Im Neuenheimer Feld 229, 69120 Heidelberg, Germany \\ ${ }^{3}$ EUMETSAT, Eumetsat Allee 1, 64295 Darmstadt, Germany \\ ${ }^{4}$ Norwegian Geotechnical Institute, Sognsveien 72, 0855 Oslo, Norway
}

Correspondence to: H. Sihler (holger.sihler@mpic.de)

Received: 28 March 2012 - Published in Atmos. Meas. Tech. Discuss.: 3 May 2012

Revised: 2 October 2012 - Accepted: 16 October 2012 - Published: 16 November 2012

\begin{abstract}
During polar spring, halogen radicals like bromine monoxide $(\mathrm{BrO})$ play an important role in the chemistry of tropospheric ozone destruction. Satellite measurements of the $\mathrm{BrO}$ distribution have become a particularly useful tool to investigate this probably natural phenomenon, but the separation of stratospheric and tropospheric partial columns of $\mathrm{BrO}$ is challenging. In this study, an algorithm was developed to retrieve tropospheric vertical column densities of $\mathrm{BrO}$ from data of high-resolution spectroscopic satellite instruments such as the second Global Ozone Monitoring Experiment (GOME-2). Unlike recently published approaches, the presented algorithm is capable of separating the fraction of $\mathrm{BrO}$ in the activated troposphere from the total $\mathrm{BrO}$ column solely based on remotely measured properties. The presented algorithm furthermore allows to estimate a realistic measurement error of the tropospheric $\mathrm{BrO}$ column. The sensitivity of each satellite pixel to $\mathrm{BrO}$ in the boundary layer is quantified using the measured UV radiance and the column density of the oxygen collision complex $\mathrm{O}_{4}$. A comparison of the sensitivities with CALIPSO LIDAR observations demonstrates that clouds shielding near-surface tracegas columns can be reliably detected even over ice and snow. Retrieved tropospheric $\mathrm{BrO}$ columns are then compared to ground-based $\mathrm{BrO}$ measurements from two Arctic field campaigns in the Amundsen Gulf and at Barrow in 2008 and 2009 , respectively. Our algorithm was found to be capable of retrieving enhanced near-surface $\mathrm{BrO}$ during both campaigns in good agreement with ground-based data. Some differences between ground-based and satellite measurements observed
\end{abstract}

at Barrow can be explained by both elevated and shallow surface layers of $\mathrm{BrO}$. The observations strongly suggest that surface release processes are the dominating source of $\mathrm{BrO}$ and that boundary layer meteorology influences the vertical distribution.

\section{Introduction}

Barrie et al. (1988) discovered bromine activation as the phenomenon behind polar ozone depletion events (ODEs) in the Arctic troposphere. Since then, considerable progress in understanding the phenomenon of ODEs has been made. However, even after two decades, key questions remain open: what are the sources of reactive halogens, what triggers their release, and what is the impact on the global tropospheric ozone budget? For a review of the current understanding of the halogen chemistry in the polar troposphere, see also Simpson et al. (2007) and references therein.

Bromine monoxide $(\mathrm{BrO})$ is a radical that catalytically destroys ozone. Its first observation from space was enabled by the Global Ozone Monitoring Experiment (GOME) instrument aboard the ERS-2 satellite (Wagner and Platt, 1998; Richter et al., 1998; Chance, 1998). Areas up to $2000 \mathrm{~km}$ across (covering several million $\mathrm{km}^{2}$ ) with elevated columns of $\mathrm{BrO}$ were detected to appear from one day to another implying local production of $\mathrm{BrO}$. $\mathrm{BrO}$ is remotely probed from space by the technique of differential optical absorption spectroscopy (DOAS) which uses 
characteristic narrow absorption bands of molecules (Platt and Stutz, 2008).

Compared to ground-based measurement techniques like long-path DOAS (LP-DOAS) (Tuckermann et al., 1997; Hausmann and Platt, 1994; Hönninger et al., 2004; Pöhler et al., 2010; Liao et al., 2011), multi-axis DOAS (MAXDOAS) (Hönninger and Platt, 2002; Hönninger et al., 2004; Wagner et al., 2007; Frieß et al., 2011), or chemical ionization mass spectrometry (CIMS) (Liao et al., 2011), observations from space offer a much better spatial coverage (at polar latitudes, full coverage is reached once per day) while temporal resolution and information about the vertical distribution is comparatively sparse. Another advantage of satellite instruments is the relatively long time of operation of several years. Satellite data sets are particularly suitable to answer open questions or test hypotheses on a more general basis (Wagner et al., 2001; Richter et al., 2002; Hollwedel et al., 2004; Kaleschke et al., 2004).

Before an existing data set on $\mathrm{BrO}$ column densities can be analyzed for tropospheric $\mathrm{BrO}$ activation, systematic errors need to be minimized. One of the largest uncertainties comes from the variability of the stratospheric $\mathrm{BrO}$ column (Wagner and Platt, 1998; Wagner, 1999; Theys et al., 2009; Salawitch et al., 2010; Choi et al., 2011) which needs to be assessed in order to study $\mathrm{BrO}$ in the troposphere from satellite observations. For extremely low tropopause heights, the stratospheric partial column may become comparable to that of a tropospheric event. When the tropopause lowers, the stratospheric air is adiabatically compressed and hence the stratospheric column of $\mathrm{BrO}$ increases additionally to an increase of the overall thickness of the stratosphere. Spatial structures mimicking tropospheric bromine events may thus appear in maps of the total $\mathrm{BrO}$ column. The challenge is to separate possible tropospheric events from stratospheric disturbances.

Several retrievals of tropospheric $\mathrm{BrO}$ columns use the output of stratospheric chemistry models for stratospheric BrO correction (Theys et al., 2009, 2011; Begoin et al., 2010; Salawitch et al., 2010; Toyota et al., 2011; Choi et al., 2011). These algorithms either use simulated stratospheric columns of $\mathrm{BrO}$ directly or derive a parameterisation of the stratospheric $\mathrm{BrO}$ column based on model results first and then apply a climatology from which the stratospheric $\mathrm{BrO}$ column is calculated using measured $\mathrm{O}_{3}$ and $\mathrm{NO}_{2}$ column data. However, chemistry models are potentially biased because the chemical mechanisms may be incomplete, and necessary parameterisations may result in systematic errors. Model results also depend on the choice of initial values which are usually difficult to obtain.

The retrieval proposed in this work overcomes these drawbacks by retrieving the parameters to estimate the stratospheric $\mathrm{BrO}$ column using only the measurements themselves. In brief, our algorithm uses the simultaneously retrieved $\mathrm{O}_{3}$ column density to account for dynamic effects and the retrieved $\mathrm{NO}_{2}$ column density to account for chemical effects. The algorithm contains the following four steps (details are given in Sect. 2.2): first, the column measurements of $\mathrm{BrO}$ and $\mathrm{O}_{3}$ are binned according to the respective $\mathrm{NO}_{2}$ column, the solar zenith angle, and the line of sight angle. In a second step, the measurements without a significantly enhanced $\mathrm{BrO} / \mathrm{O}_{3}$ column ratio are considered to calculate the mean stratospheric $\mathrm{BrO} / \mathrm{O}_{3}$ column ratio within each bin. Then, the stratospheric $\mathrm{BrO}$ column for each pixel is calculated using the measured $\mathrm{O}_{3}$ and $\mathrm{NO}_{2}$ column densities and the solar zenith angle. Finally, the difference between measured total and calculated stratospheric column yields a residual $\mathrm{BrO}$ column. This approach is completely independent from models.

In a second step, an algorithm assuring the sensitivity of the satellite measurement towards $\mathrm{BrO}$ located in the boundary layer (BL) is developed and also included in the retrieval. Hence, it is possible to study surface processes involved in bromine activation on a per-pixel basis. Parameters affecting this sensitivity are the surface albedo as well as the thickness and height of overlying clouds. In polar regions, the detection of clouds from satellites is particularly difficult for instruments measuring in the UV and visible spectral range due to ambiguities between cloud particles and the ice- or snow-covered underlying surface. Various studies to measure optical properties of clouds over ice in polar regions from space (e.g. Vasilkov et al., 2010; O’Byrne et al., 2010) are based on data from a multitude of sensors and satellites. The ice-mode of FRESCO+ (Fast Retrieval Scheme for Clouds from the Oxygen A band, Koelemeijer et al., 2001; Wang et al., 2008) derives the surface height of a Lambertian reflector with monthly averaged climatological albedo value using $\mathrm{O}_{2}$ absorption measurements. In this work, we chose a slightly different approach: individual reflectances are combined with the corresponding differential absorption of the $\left(\mathrm{O}_{2}\right)_{2}$ collision complex (denoted $\mathrm{O}_{4}$ in this work) in order to assure the sensitivity above a given threshold. The scale height of $\mathrm{O}_{4}$ is approx. $4 \mathrm{~km}$ (Greenblatt et al., 1990; Acarreta et al., 2004) thus providing a better sensitivity to nearsurface concentrations compared to $\mathrm{O}_{2}$.

This paper is organized as follows: in Sect. 2 we describe our new algorithm to retrieve tropospheric columns of $\mathrm{BrO}$ during periods of halogen activation in Arctic spring. Different parts of the algorithm are either compared to simulated data or measurements from other satellite instruments in Sect. 3. Retrieved tropospheric BrO columns are compared with ground-based measurements of $\mathrm{BrO}$ obtained during two field campaigns to the Arctic in 2008 and 2009 (Sect. 4). Conclusions are drawn in Sect. 5.

\section{Spectral evaluation, column separation and sensitivity filter}

The GOME-2 instrument (second Global Ozone Monitoring Experiment) is a high-resolution nadir scanning spectrometer 
aboard the MetOp-A satellite (e.g. Callies et al., 2000; Munro et al., 2006). MetOp-A, launched in 2006, is the first of a series of three polar-orbiting satellites of identical design. The satellite is flying in a sun-synchronous orbit crossing the Equator at 09:30 LT. It is a platform for a set of instruments primarily designed for meteorological applications. Data from two of these instruments - the AVHRR (Advanced Very High Resolution Radiometer) and GOME-2 - are used in this study. The retrieval of tropospheric columns of $\mathrm{BrO}$ from GOME-2 is the main focus, while AVHRR data will later be applied to evaluate the sensitivity to near-surface trace-gas concentrations (Sect. 3.3).

GOME-2 has four main spectral channels in the UV/vis spectral range between 240 and $790 \mathrm{~nm}$. The instrument scans in a whisk-broom scheme with a swath-width of $1920 \mathrm{~km}$, which allows an almost global coverage each day. Polar regions, however, are sampled several times a day. The nominal ground pixel size is approx. $80 \times 40 \mathrm{~km}^{2}$ with an integration time of $187.5 \mathrm{~ms}$ per spectrum.

Three fundamental steps are needed in order to retrieve a residual tropospheric vertical column density of $\mathrm{BrO}$

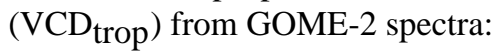

i. retrieval of total slant column densities (SCDs) of $\mathrm{BrO}$, $\mathrm{O}_{3}, \mathrm{NO}_{2}$, and $\mathrm{O}_{4}$ from Earth radiance spectra using the DOAS method (Sect. 2.1).

ii. separation into a stratospheric and residual tropospheric BrO SCD and error estimation (Sect. 2.2). The main concept behind the algorithm is described in Sect. 2.2.1 followed by its implementation in Sect. 2.2.2.

iii. calculation of $\mathrm{VCD}_{\text {trop }}$ using a tropospheric air-mass factor (AMF) retrieved from $\mathrm{O}_{4} \mathrm{SCD}$ and reflectance measurements (Sect. 2.3). The algorithm, which is also capable of filtering measurements with a low sensitivity to near-surface concentrations of $\mathrm{BrO}$, is described in Sect. 2.3.1, and its implementation in Sect. 2.3.2.

The results from the retrieval as well as its advantages and disadvantages are discussed in Sect. 2.4.

\subsection{Evaluation of GOME-2 spectra}

Differential optical absorption spectroscopy (DOAS) is a common technique to derive slant column densities of numerous trace-gases in the atmosphere (Platt and Stutz, 2008). In this work, DOAS is applied in three different wavelength ranges to derive $\mathrm{SCDs}$ of $\mathrm{BrO}, \mathrm{O}_{3}, \mathrm{O}_{4}$ and $\mathrm{NO}_{2}$ from calibrated GOME- 2 spectra. Table 1 summarizes the parameters and molecular absorption cross-sections applied in the DOAS evaluation.

For the retrieval of BrO SCDs, several modifications compared to previously published retrievals are applied to the settings of the DOAS fit. The wavelength range between 336 and $360 \mathrm{~nm}$ combines the standard wavelength ranges used for the first GOME (Wagner and Platt, 1998; Aliwell et al.,
2002) and the Scanning Imaging Absorption Spectrometer for Atmospheric Chartography (SCIAMACHY) (Afe et al., 2004; De Smedt et al., 2004) instruments and encompasses four absorption bands of the $\mathrm{BrO}$ molecule. Furthermore, formaldehyde ( $\mathrm{HCHO}$ ) was excluded from the spectral evaluation in order to reduce the noise level of the $\mathrm{BrO}$ retrieval. This approach is appropriate when only polar regions are taken into account where $\mathrm{HCHO}$ abundances are generally low. In addition to molecular absorption cross-sections, two spectra are included in the evaluation procedure to account for the wavelength-dependent Ring effect (Grainger and Ring, 1962) following the suggestions of Wagner et al. (2009a); both are calculated and normalised using the DOASIS software version 3.2 (Kraus, 2004). Furthermore, a reciprocal intensity spectrum is included in the fit in order to account for possible stray light within the instrument. A fourth-order polynomial is finally included to account for broad-band effects like surface reflection as well as Mie and Rayleigh scattering.

The fit result provides total SCDs of BrO $S$, which need to be subsequently normalised for several reasons: (i) the SCDs of weak absorbers potentially contain an unknown offset due to spectral structures varying over time as discussed by Richter et al. (2002); (ii) the GOME-2 instrument suffers from sensor degradation leading to increased statistical and, more problematic, systematic errors of the BrO SCDs as revealed by Dikty et al. (2011); (iii) the proposed retrieval algorithm for tropospheric BrO VCDs is intended to be applicable also on satellite sensors other than the GOME-2 on MetOp-A. The normalisation step introduces the possibility to homogenise the $\mathrm{BrO}$ data gained from the measurements of different satellite instruments.

Measured BrO SCDs are normalised to a VCD of $V_{\text {norm }}=3.5 \times 10^{13} \mathrm{molec}^{-2}$ within a reference sector over the Pacific Ocean as suggested by Richter et al. (2002). This normalisation is performed for each pixel number of one scan separately (GOME-2: 32 pixels per scan; pixel numbers correspond to discrete VZA angles). The boundaries of the reference sector are $\pm 10^{\circ}$ latitude and $150^{\circ} \mathrm{E}$ to $100^{\circ} \mathrm{W}$ longitude. Pixels with a footprint significantly different from the nominal $\approx 80 \times 40 \mathrm{~km}^{2}$ (narrow-mode and backscan pixels) are excluded from counting as reference measurements. The normalised SCDs $S$ are calculated by subtracting the median difference between SCDs in the reference sector and the normalised SCD $S_{\text {norm }}=V_{\text {norm }} \cdot A_{\text {geom }}$ from the measured SCDs applying the geometrical AMF $A$ geom. While the AMF is defined as the ratio of SCD and VCD in general, $A$ geom displays an adequate approximation for stratospheric absorbers for $\mathrm{SZA}<80^{\circ}$. Ageom is defined as

$A$ geom $=\frac{1}{\cos \vartheta}+\frac{1}{\cos \psi}$

where $\vartheta$ denotes the SZA, and $\psi$ denotes the viewing zenith angle (VZA). 
Table 1. Compilation of fit ranges, reference cross-sections and parameters of the three DOAS evaluations of calibrated radiance spectra measured by GOME-2. The slant column densities (SCDs) of $\mathrm{BrO}, \mathrm{O}_{3}, \mathrm{O}_{4}$ and $\mathrm{NO}_{2}$ are retrieved. The synthetic Ring spectra account for (wavelength-dependent) inelastic Raman scattering, and the reciprocal intensity spectrum accounts for instrumental stray light (see text). The fit-polynomial models broadband absorption.

\begin{tabular}{|c|c|c|c|}
\hline Retrieved SCD & $\mathrm{BrO}$ and $\mathrm{O}_{3}$ & $\mathrm{O}_{4}$ & $\mathrm{NO}_{2}$ \\
\hline GOME-2 band & $2 \mathrm{~B}$ & $2 \mathrm{~B}$ & 4 \\
\hline Pixel number & $301-503$ & $459-759$ & $185-288$ \\
\hline Wavelength (nm) & $336-360$ & $355-390$ & $431-453$ \\
\hline $\mathrm{O}_{3}(243 \mathrm{~K})$ & Gür et al. (2005) & $*$ & - \\
\hline $\mathrm{O}_{3}(223 \mathrm{~K})$ & Gür et al. (2005) & - & - \\
\hline $\mathrm{O}_{3}(221 \mathrm{~K})$ & - & - & Burrows et al. (1998) \\
\hline $\mathrm{BrO}(228 \mathrm{~K})$ & Wilmouth et al. (1999) & - & - \\
\hline $\mathrm{O}_{4}$ & Greenblatt et al. (1990) & $*$ & $*$ \\
\hline $\mathrm{NO}_{2}(220 \mathrm{~K})$ & Vandaele et al. (1998) & $*$ & $*$ \\
\hline $\mathrm{OClO}(293 \mathrm{~K})$ & Bogumil et al. (2003) & - & - \\
\hline $\mathrm{SO}_{2}(273 \mathrm{~K})$ & Bogumil et al. (2003) & - & - \\
\hline $\mathrm{H}_{2} \mathrm{O}(300 \mathrm{~K})$ & 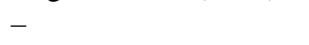 & - & Rothman et al. (1992) \\
\hline $\mathrm{CHOCHO}$ & - & - & Volkamer et al. (2005) \\
\hline $\operatorname{Ring} \times \lambda^{4}$ & yes & yes & no \\
\hline Ring (norm) & yes & yes & yes \\
\hline Reciprocal & yes & yes & no \\
\hline Polynomial & 4 th order & 3rd order & 4 th order \\
\hline
\end{tabular}

The asterisk $(*)$ denotes that the reference in the column to the left is applied.

Total VCDs $V$ of BrO can be approximated from $S$ using

$V=\frac{S}{A \text { geom }}$

again applying $A$ geom. As an example, total VCDs of $\mathrm{BrO}$ measured on 25 March 2009 over the Arctic are plotted in Fig. 1a.

Owing to the strong differential structure of ozone, the $\mathrm{SCD}$ of $\mathrm{O}_{3}$ may also be derived from the same DOAS evaluation as $\mathrm{BrO}$ at much higher signal-to-noise ratio. The $\mathrm{O}_{3}$ SCD is calculated as the sum of the fit results of both $\mathrm{O}_{3}$ references corresponding to different temperatures. This approach of a retrieval for $\mathrm{O}_{3}$ potentially leads to SCDs with a systematic error which, however, cancels out later during the parameterisation of the stratospheric BrO-column (Sect. 2.2). $\mathrm{O}_{3}$ VCDs computed from $\mathrm{O}_{3}$ SCDs using $A$ geom are shown in Fig. 1b for 25 March 2009.

Using radiances in another wavelength interval, the SCD of the oxygen collision complex $\left(\mathrm{O}_{4}\right)$ is retrieved in the range between 355 and $390 \mathrm{~nm}$ using the setting compiled in Table 1 . This spectral range includes two absorption bands of $\mathrm{O}_{4}$ at $360 \mathrm{~nm}$ and $380 \mathrm{~nm}$.

Finally, the $\mathrm{SCD}$ of $\mathrm{NO}_{2}$ is retrieved from radiances measured in band 4 of the GOME-2 instrument in the range between $431 \mathrm{~nm}$ and $453 \mathrm{~nm}$. In contrast to the previous two settings, a single Ring spectrum (also calculated using the DOASIS software) was found to be sufficient due to a weaker Raman signal at longer wavelengths in connection with the rather narrow fit range.

\subsection{Separation of tropospheric and stratospheric BrO slant-columns}

This section describes how the measured total SCD of BrO is separated into background stratospheric and residual tropospheric column density $S_{\text {strat }}$ and $S_{\text {trop }}$, respectively.

$S=S_{\text {strat }}+S_{\text {trop }}$

Furthermore, the standard deviation of the measurement $\sigma_{0}$ of $\mathrm{BrO}$ is estimated. This allows to evaluate the significance of a possible tropospheric signal. For the sake of clarity, SCDs $S$ and VCDs $V$ without subscripted chemical formula denote $\mathrm{BrO}$ column densities throughout the paper.

\subsubsection{Concept of the BrO column separation}

The main task of the $\mathrm{BrO}$ column separation is to compute the SCD of $\mathrm{BrO}$ contained in the stratosphere, $S_{\text {strat }}$. Two substances, $\mathrm{O}_{3}$ and $\mathrm{NO}_{2}$, are used to parametrise $S_{\text {strat }}$ similar to the approach initially proposed by Theys et al. (2009) but without utilising any model output. $\mathrm{O}_{3}$ is chosen as a parameter for tropopause dynamics, whereas $\mathrm{NO}_{2}$ is used as a parameter for variations in the stratospheric chemistry.

The ratio $z_{0}$ of the stratospheric $\mathrm{BrO} S C D$ to the $\mathrm{O}_{3} \mathrm{SCD}$, $S_{{\text {Strat }, \mathrm{O}_{3}}_{3} \text {, is defined as }}$

$z_{0}=\frac{S_{\text {strat }}}{S_{{\text {strat }, O_{3}}}}$

where $S_{\mathrm{Strat}_{, \mathrm{O}_{3}}}$ is expressed in molec $\mathrm{cm}^{-2}$ using the definition of the Dobson unit $\left(1 \mathrm{DU}=2.69 \times 10^{16} \mathrm{molec} \mathrm{cm}^{-2}\right)$. 

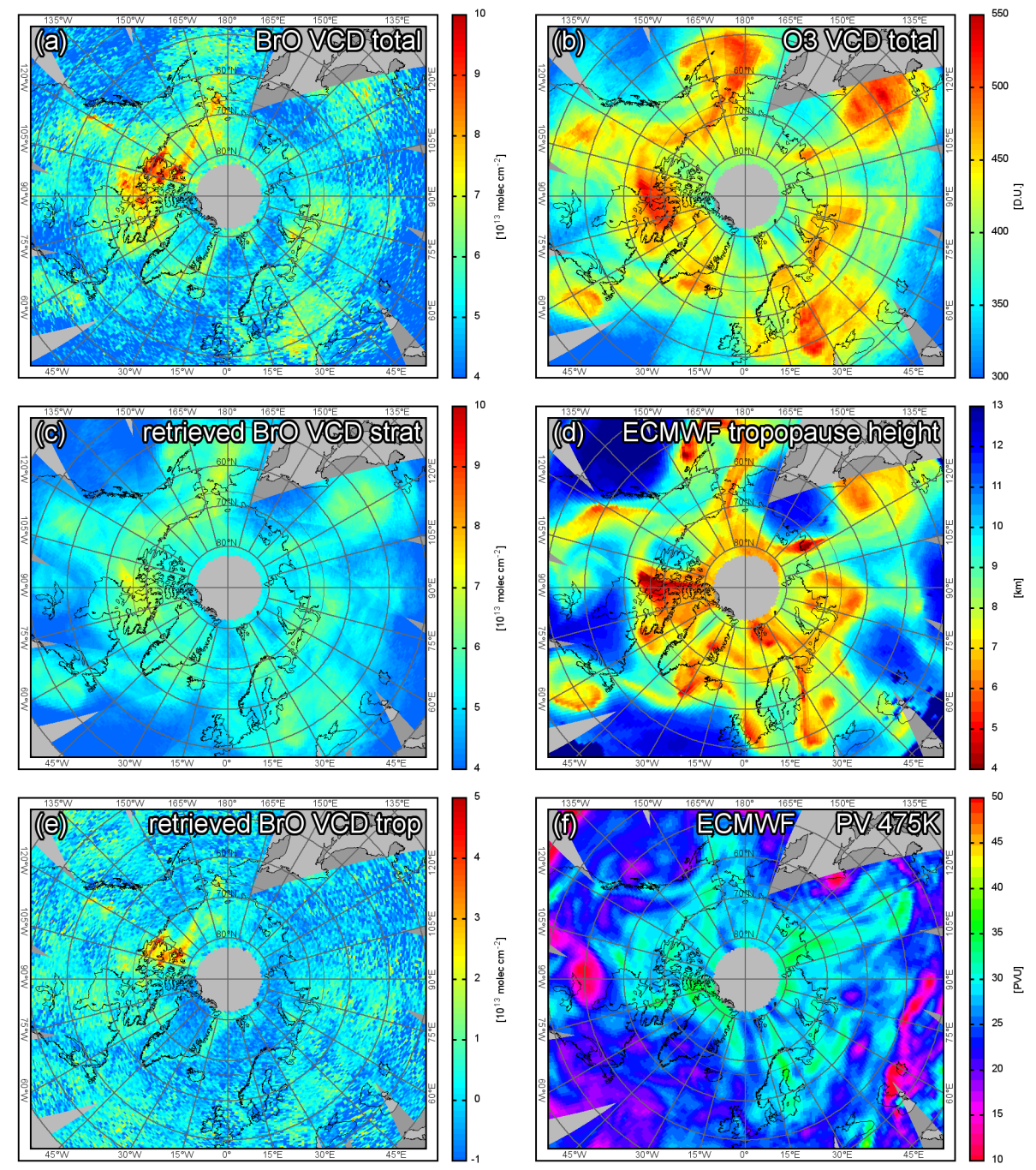

Fig. 1. Illustration of the decomposition of the total BrO VCD measured by GOME-2 into stratospheric and tropospheric contribution for 25 March 2009. The top row shows VCDs of $\mathrm{BrO}$ (a) and $\mathrm{O}_{3}$ (b) assuming a geometric AMF. Coinciding spatial structures of enhanced VCDs are visible e.g. over Eastern Europe and Northern Siberia, which are attributed to stratospheric dynamics and variations of the tropopause height (d). The $\mathrm{BrO} \mathrm{SCD}$ strat (c) is retrieved from measurements of $\mathrm{BrO}, \mathrm{O}_{3}$, and $\mathrm{NO}_{2}$ alone. The $\mathrm{BrO} \mathrm{VCD}$ trop (e) is the difference between (a) and (c). The PV at the 475K isentrope (f) may be used to identify regions within the polar vortex (see Sect. 2.2.2). All VCDs are calculated using a geometric AMF; gray areas contain no data.

Knowing $z_{0}$ and $S_{\mathrm{Strat} \mathrm{O}_{3}}$ would allow us to compute the $\mathrm{SCD}$ of BrO directly,

$S_{\text {strat }}=S_{\text {strat }, \mathrm{O}_{3}} \cdot z_{0}$.

This approach implicitly relies on similar vertical profiles of $\mathrm{BrO}$ and $\mathrm{O}_{3}$, which is further discussed in Sect. 3.2. However, measurement data obtained by GOME-2 furnish us only with a set of values of the ratio $z$ between the total BrO SCD $S$ and of the total $\mathrm{O}_{3} \mathrm{SCD} \mathrm{S}_{3}$ in the stratosphere and troposphere combined:

$z=\frac{S}{S_{\mathrm{O}_{3}}}$.
Since almost the entire $\mathrm{O}_{3}$ column is located in the stratosphere, $z$ becomes

$z=\frac{S_{\text {strat }}+S_{\text {trop }}}{S_{\text {strat }, \mathrm{O}_{3}}}=z_{0}+z^{\prime}$,

where $z^{\prime}$ is defined as the ratio between $S_{\text {trop }}$ and $S_{\text {strat, }{ }_{3}}$. In addition, measurement errors are included in $z$, which allows us to write

$z=\bar{z}_{0}+\zeta_{\sigma_{0}}+z^{\prime}$

where $\bar{z}_{0}$ is the mean of $z_{0}$ and $\zeta_{\sigma_{0}}$ is Gaussian distributed with zero mean and $\sigma_{0}$ standard deviation. The quantity $z^{\prime}$ can be interpreted as an error contribution due to elevated 
concentrations of $\mathrm{BrO}$ in the troposphere. The distribution of $z^{\prime}$ is unknown a priori. However, it leads to an overestimation of $S_{\text {strat }}$, if the simple mean $\bar{z}$ is used as an estimator for $\bar{z}_{0}$. The ratio $z_{0}$ in the stratosphere, Eq. (4), depends mainly on the stratospheric $\mathrm{NO}_{2}$ chemistry which is parameterised by the VCD of $\mathrm{NO}_{2}$ and the SZA.

The stratospheric chemistry leads to significant deviations between $S_{\text {strat }}$ and $S_{\text {strat, } \mathrm{O}_{3}}$. The partitioning of inorganic bromine species $\mathrm{Br}_{\mathrm{y}}=\left\{\mathrm{BrO}+\mathrm{BrONO}_{2}+\mathrm{Br}_{2}+\mathrm{HOBr}+\right.$ $\mathrm{HBr}+\ldots\}$ is not constant (Dorf et al., 2006; Theys et al., 2009; Salawitch et al., 2010). It turns out that the $\mathrm{BrO} / \mathrm{Br}_{\mathrm{y}}$ concentration ratio, which is typically of the order of 0.6 during daytime, depends primarily on the stratospheric $\mathrm{NO}_{2}$ concentration. This is due to the fact that $\mathrm{NO}_{2}$ acts as a sink for stratospheric $\mathrm{BrO}$ producing bromine nitrate $\left(\mathrm{BrONO}_{2}\right)$ :

$\mathrm{BrO}+\mathrm{NO}_{2}+\mathrm{M} \longrightarrow \mathrm{BrONO}_{2}+\mathrm{M}$,

which decreases the $\mathrm{BrO}$ concentration while leaving the concentration of $\mathrm{Br}_{\mathrm{y}}$ unchanged. $\mathrm{BrONO}_{2}$ is the second most abundant $\mathrm{Br}_{\mathrm{y}}$-species during daylight (e.g. Sinnhuber et al., 2002; Atkinson et al., 2007; Theys et al., 2009). The main loss mechanism of $\mathrm{BrONO}_{2}$, however, is photolysis leading to a quasi-stationary state between $\mathrm{BrO}$ and $\mathrm{BrONO}_{2}$ depending on the $\mathrm{NO}_{2}$ concentration and the actinic flux.

As a result, the ratio $z_{0}$ in Eq. (4) decreases with increasing concentration of $\mathrm{NO}_{2}$ also depending on the SZA $\vartheta$ determining the actinic flux. The concentration of $\mathrm{NO}_{2}$ is not accessible from nadir measurements alone, and therefore the $\mathrm{NO}_{2}$ vertical column density $V_{\mathrm{N}}$ is used in the column separation process instead. Furthermore, our algorithm also accounts for a slight dependence of $z_{0}$ on the VZA $\psi$. The stratospheric BrO SCD $S_{\text {strat }}$ is therefore mainly a function of $\vartheta, V_{\mathrm{N}}$, and $\psi$ :

$S_{\text {strat }}\left(\vartheta, V_{\mathrm{N}}, \psi\right)=S_{{\text {Strat }, O_{3}}_{3}} \cdot \bar{z}_{0}\left(\vartheta, V_{\mathrm{N}}, \psi\right)$.

Unfortunately, however, the assumptions made so far are not applicable to the chemistry inside the polar vortex and during ozone-hole conditions. Extremely cold temperatures alter the chemistry of the stratosphere rendering reaction Eq. (9) insufficient to describe the chemistry affecting BrO. Moreover, there can be massive chemical loss of stratospheric $\mathrm{O}_{3}$ so that $S_{\mathrm{Strat} \mathrm{O}_{3}}$ can no longer be used to account for dynamical effects. Therefore, our algorithm in its present form is inapplicable for an estimation of the stratospheric $\mathrm{BrO}$ within the polar vortex occurring in springtime Antarctica in general and in some areas of the Northern Hemisphere during winters with low stratospheric temperatures as depicted in Fig. 2.

Finally, in order to compute $S_{\text {strat }}$ as a function of $\vartheta, V_{\mathrm{N}}$, and $\psi$, we need to compute $\bar{z}_{0}\left(\vartheta, V_{\mathrm{N}}, \psi\right)$ from

$z\left(\vartheta, V_{\mathrm{N}}, \psi\right)=\bar{z}_{0}\left(\vartheta, V_{\mathrm{N}}, \psi\right)+\zeta_{\sigma\left(\vartheta, V_{\mathrm{N}}, \psi\right)}+z^{\prime}\left(\vartheta, V_{\mathrm{N}}, \psi\right)$.

The precise procedure of how this is done is explained in the following subsection.

\subsubsection{Implementation of the column separation algorithm}

This section describes the implementation of the algorithm to calculate the tropospheric SCD of BrO. The algorithm is divided into four steps: (i) selection of reference measurements for one day and partitioning of reference measurements in the $\left(\vartheta, V_{\mathrm{N}}\right)$-plane for five different $\psi$-ranges; (ii) calculation of $\bar{z}_{0}$ and $\sigma_{0}$ in each partition after filtering significantly enhanced $z^{\prime}$; and (iii) mapping of $\bar{z}_{0}\left(\vartheta, V_{\mathrm{N}}, \psi\right)$ on all observations and calculation of $S_{\text {strat }}$ according to Eq. (10).

The statistical analysis to retrieve $\bar{z}_{0}$ requires a sufficiently large base population of measurements $T_{0}$. The analysis is performed separately for each day $D$. In order to increase the size of $T_{0}$, all measurements within a 7-day period $P=$ $[D-3, D+3]$ are considered. This approach improves the statistical significance and reduces noise. It is similar to a running average filter and relies on a stratospheric chemistry changing only slightly within one week.

i. A subset $T \subset T_{0}$ of measurements is selected to avoid interferences with anthropogenic $\mathrm{NO}_{2}$ emissions and to increase the accuracy of the stratospheric information in the nadir observations. $T$, from which the stratospheric correction is computed, contains only those observations with an SZA smaller than $80^{\circ}$, latitudes above $30^{\circ} \mathrm{N}$, a fit-error for $\mathrm{BrO}$ smaller than $5 \times 10^{13} \mathrm{molec}^{-2}$, an $\mathrm{O}_{4} \mathrm{SCD}$ larger than $6.5 \times 10^{42} \mathrm{molec}^{2} \mathrm{~cm}^{-5}$, and a non-negative $\mathrm{NO}_{2}$ VCD smaller than $8 \times 10^{15}$ molec $\mathrm{cm}^{-2}$ below $60^{\circ} \mathrm{N}$. Narrow-mode and backscan pixels are excluded from $T$ as well as potential measurements within the polar vortex, as for example depicted in Fig. 2f. Areas inside the polar vortex are identified using information about the potential vorticity derived from meteorological model data (ECMWF operational analysis, regular $1^{\circ} \times 1^{\circ}$ grid with 91 hybrid pressure levels, $6 \mathrm{~h}$ time resolution). Columns exceeding a potential vorticity of $35 \mathrm{PVU}$ at the $475 \mathrm{~K}$ isentrope surface or $75 \mathrm{PVU}$ at $550 \mathrm{~K}$ are discarded from the further analysis. Furthermore, $T$ does not contain any measurements with a ground elevation above $1000 \mathrm{~m}$ and no measurements over land masses at latitudes below $73^{\circ} \mathrm{N}$. The latter selection rule accounts for areas with a strong anthropogenic $\mathrm{NO}_{2}$ signal like Prudhoe Bay or Norilsk which would interfere with the algorithm. After applying these filters, the final subset $T$ contains $N_{\alpha} \approx 10^{5}$ reference observations for each day from which the stratospheric $\mathrm{BrO}$ column is estimated.

ii. A mean stratospheric $\mathrm{BrO} / \mathrm{O}_{3}$ background ratio $\bar{z}_{0}\left(\vartheta, V_{\mathrm{N}}, \psi\right)$ is calculated from $T$. Obtaining an estimate of $\bar{z}_{0}$, Eq. (11), by measured values of $z_{\alpha} \in T$ with coordinates $\left(\vartheta_{\alpha}, V_{\mathrm{N}_{\alpha}}, \psi_{\alpha}\right), \alpha=1, \ldots, N_{\alpha}$, containing an arbitrary error with a Gaussian and a positive unknown contribution, requires a technique of approximating a function on an unstructured set of points 

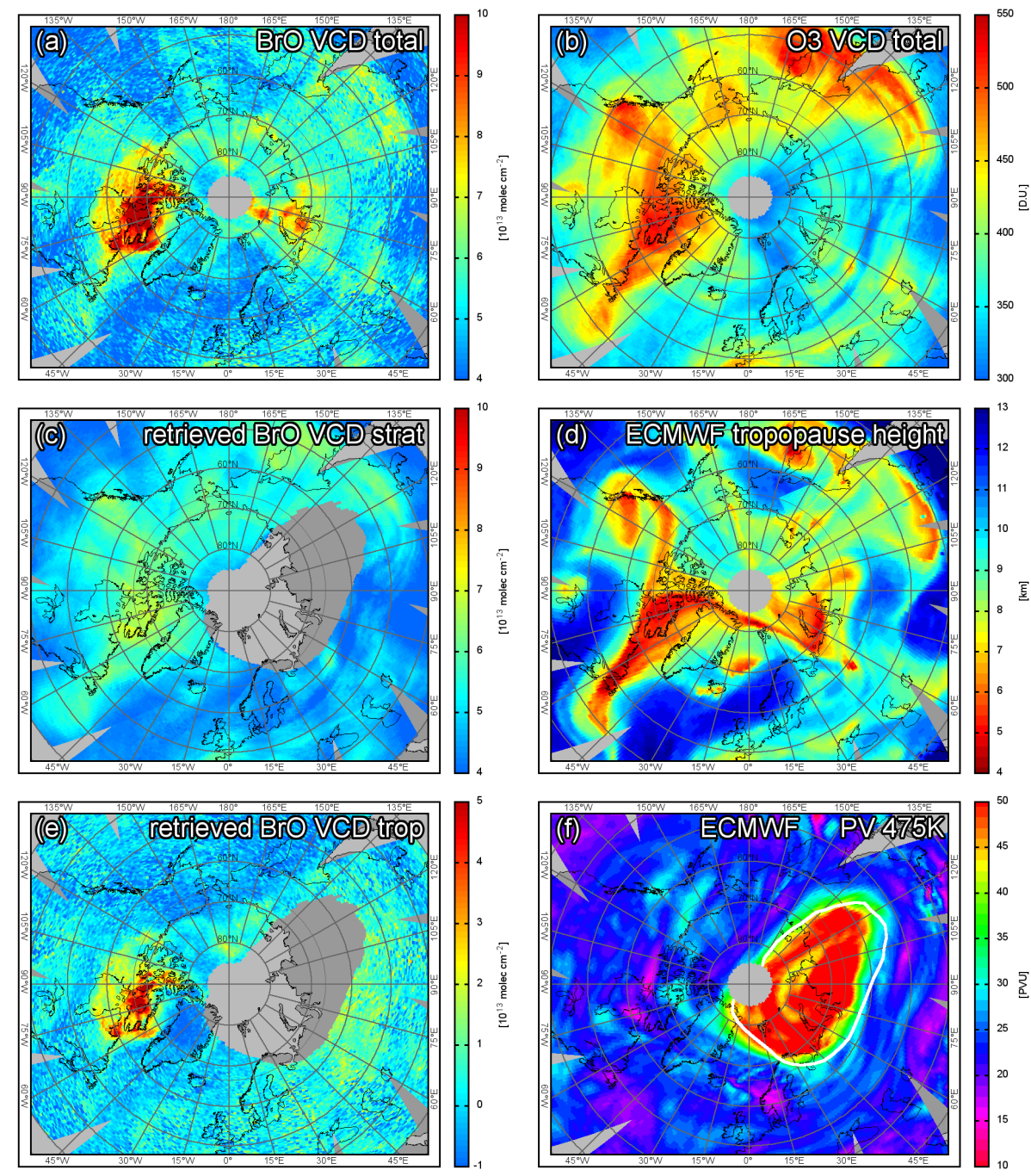

Fig. 2. Same as in Fig. 1, but for 1 April 2007. The white contour in (f) marks the 75 PVU-isoline at the $550 \mathrm{~K}$ isentrope. The decomposition into stratospheric and tropospheric column fails within the polar vortex, because there is no clear correlation between $\mathrm{O}_{3} \mathrm{VCD}$ and the tropopause height (d) any more.

where the data to be approximated contain uncertainties. Traditionally, least-squares approximations (Quarteroni et al., 2002) are used to approximate scattered data. More elaborate methods use radial basis functions or kriging (Press et al., 2007) in order to treat scattered data. Common to these methods is that some knowledge about the distribution, such as the variance, is necessary in order to compute an approximant. In addition, they are relatively costly, given that the number of measured values $N_{\alpha}$ is large $\left(\approx 10^{5}\right)$, making it necessary to have an efficient method to process a large number of these data sets.

For the method proposed in this paper, we take advantage of the fact that the function $\bar{z}_{0}\left(\vartheta, V_{\mathrm{N}}, \psi\right)$ depends only weakly on $\vartheta, V_{\mathrm{N}}$, and $\psi$. In addition, we use trilinear interpolation in order to avoid spurious oscillations which can occur when using polynomials of higher degree. Since $\bar{z}_{0}$ depends only weakly on $\vartheta$, $V_{\mathrm{N}}$, and $\psi$, we can regroup the measured $z$ in subsets for which $\bar{z}_{0}$ is almost constant. For a domain $\Omega=\left[\vartheta_{a}, \vartheta_{b}\right] \times\left[V_{\mathrm{N}_{a}}, V_{\mathrm{N}_{b}}\right] \times\left[\psi_{a}, \psi_{b}\right]$, this boils down to finding a partition $\Omega_{\beta}, \beta=1, \ldots, N_{\beta}$ of $\Omega$, such that $\Omega_{\beta}$ contains enough points to allow for statistics on $z_{\alpha}$ for which $\left(\vartheta_{\alpha}, V_{\mathrm{N}_{\alpha}}, \psi_{\alpha}\right) \in \Omega_{\beta}$. On the other hand, $\Omega_{\beta}$ should be small enough, such that $\bar{z}_{0}$ does not vary too much with respect to $\vartheta, V_{\mathrm{N}}$, and $\psi$ in $\Omega_{\beta}$. It is clear that such a partition, as shown in Fig. 3, is not unique and that the shape of the subsets $\Omega_{\beta}$ might influence the accuracy of the present method. In Appendix A, we present in more detail how $\Omega$ is partitioned in quadrilaterals, allowing a trilinear reconstruction of $\bar{z}_{0}$. 


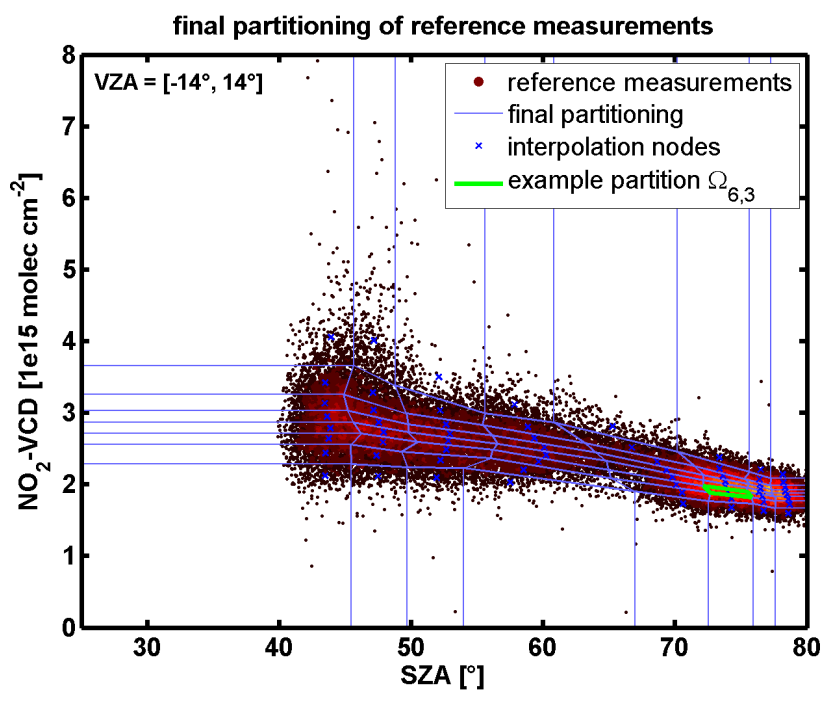

Fig. 3. Partitioning of GOME-2 reference measurements (colourcoded density) in the $\left(\vartheta, V_{\mathrm{N}}\right)$-plane for the near-nadir direction $\left(|\psi| \leq 14^{\circ}\right)$ for 25 March 2009. Each partition contains an almost equal number of measurements from which $\mathrm{BrO} / \mathrm{O}_{3} \mathrm{SCD}$ ratios are retrieved. The example partition $\Omega_{6,3}$ is depicted in Fig. 4 . The mean of measurements within each partition (blue crosses) is used as nodes for interpolating the results (Fig. 5).

For each partition $\Omega_{\beta}$, a filter algorithm is applied as presented in the following. The filter algorithm is based on the assumption that an ensemble of $z$ is normally distributed around $\bar{z}_{0}$. Significant outliers, if any, are mostly due to enhancements of the tropospheric $\mathrm{BrO}$ column and, to a lesser degree, due to a partially depleted $\mathrm{O}_{3}$ column. Both effects lead to an increase of a particular $z$ by $z^{\prime}$ in Eq. (11), which in turn leads to an increasing asymmetry of the otherwise symmetric normal distributed $z$ (Fig. 4). The asymmetry $a_{\beta}$ of the distribution of $z=z\left(\Omega_{\beta}\right)$ in partition $\Omega_{\beta}$ is defined as

$a_{\beta}(z)=\frac{\bar{z}-\tilde{z}}{\sigma}$,

where $\bar{z}$ denotes the mean, $\tilde{z}$ the median, and $\sigma$ the standard deviation of $z$. If $a_{\beta}$ is larger than a threshold, i.e. the distribution is skewed towards higher $\mathrm{BrO} / \mathrm{O}_{3}$ $\mathrm{SCD}$ ratios, a subset of $z$ accounting for the stratosphere needs to be calculated before $\bar{z}$ and $\sigma$ can be used as estimators for $\bar{z}_{0}$ and the standard deviation $\sigma_{0}$ of $z_{0}$, respectively.

A filter algorithm is designed to find a subset of $z$ with a symmetric distribution identified as the stratospheric mode (Fig. 4). The asymmetry of the distribution of $z$ is iteratively minimized by cropping values with an offset $\Delta z=|z-\bar{z}|$ larger than a given threshold $\delta z$. In step $k$ of the iteration, the asymmetry $a_{k}$ of the distribution of

$z_{k}=\left\{z \mid-\delta z_{k}<z-\bar{z}_{k-1}<\delta z_{k}\right\}$

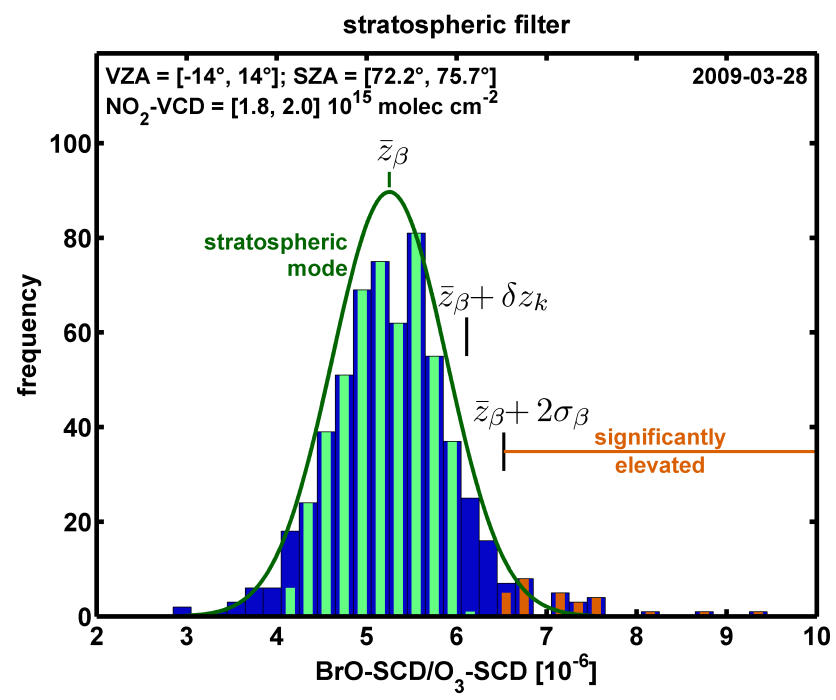

Fig. 4. Frequency distribution of measured $\mathrm{BrO} \mathrm{SCD}$ to $\mathrm{O}_{3} \mathrm{SCD}$ ratios (blue) from the example partition $\Omega_{6,3}$ in Fig. 3. The algorithm retrieves the limits of a subdivision with minimal asymmetry (green) containing mostly measurements of the stratospheric background. Significantly enhanced measurements (high $\mathrm{BrO}$, low $\mathrm{O}_{3}$ ) appear in the right tail of the distribution (red). See text for details.

is calculated with $\bar{z}_{k-1}$ denoting the mean of the distribution in the previous step. Starting with $\delta z_{0}=$ $\max (z)-\bar{z}$, the threshold $\delta z_{k}$ is iteratively decreased until $a_{k} \leq 0.001$ or a maximum of $k=20$ steps is reached (see green bars in Fig. 4). The minimal asymmetry calculated from this algorithm is limited by numerical accuracy, and the termination condition of 0.001 was found to provide still a reasonably small residual asymmetry of the output. The result is a filtered mean $\bar{z}_{\beta}=\bar{z}_{k}$. The standard deviation $\sigma_{\beta}$, however, is not calculated based on the cropped distribution of $z_{k}$. This approach would lead to an underestimation of the true standard deviation, because the cropped distribution (green bars in Fig. 4) has a larger kurtosis than the normal distribution. Therefore, it is computed only using measurements with $z_{m}<\bar{z}_{\beta}$ and

$\sigma_{\beta}=\sqrt{\frac{1}{n-1} \sum_{m}\left(z_{m}-\bar{z}_{k}\right)^{2}}$

because this selection is assumed not to include any measurements with a significant tropospheric signal.

iii. The above computed values $\bar{z}_{\beta}$ and $\sigma_{\beta}$ are mapped to the center of gravity of the points $\left(\vartheta_{\alpha}, V_{\mathrm{N}_{\alpha}}, \psi_{\alpha}\right)$ in $\Omega_{\beta}$ and used for trilinear interpolation, which furnishes us two functions: $\bar{z}_{0}\left(\vartheta, V_{\mathrm{N}}, \psi\right)$ and $\sigma_{0}\left(\vartheta, V_{\mathrm{N}}, \psi\right)$. Now, the $\mathrm{SCD}$ of $\mathrm{BrO}$ in the stratosphere $S_{\mathrm{strat}}$ and its standard deviation, $\sigma_{\text {strat }}$, can be computed by 
Table 2. Summary of all modelled geometries for which the threshold parametrization is performed. The solar zenith angle (SZA), relative azimuth angle (RAA), and viewing zenith angle (VZA) are defined in the satellite system, respectively.

\begin{tabular}{ll}
\hline Parameter & Node \\
\hline SZA $\left(^{\circ}\right)$ & $28,44,56,64,66,68,72,76,80,82,84,86$ \\
RAA $\left(^{\circ}\right)$ & $0,20,32,36,44,48,52,56,60,64,116,120$, \\
& $124,128,132,136,144,148,160,180$ \\
VZA $\left({ }^{\circ}\right)$ & 0 (nadir) $16,32,48$ \\
Elev. $(\mathrm{km})$ & $0,1,2,3,4,5,6$ \\
\hline
\end{tabular}

$S_{\text {strat }}=S_{\text {strat }, \mathrm{O}_{3}} \cdot \bar{z}_{0}\left(\vartheta, V_{\mathrm{N}}, \psi\right)$

$\sigma_{\text {strat }}=S_{\text {strat }, \mathrm{O}_{3}} \cdot \sigma_{0}\left(\vartheta, V_{\mathrm{N}}, \psi\right)$.

As an example, Figs. 1e and 2e illustrate the resulting tropospheric $\mathrm{BrO} \mathrm{VCD}$ for 25 March 2009 and 1 April 2008, respectively. It is interesting to note that, as depicted in Fig. 5a, the retrieved $\mathrm{BrO} / \mathrm{O}_{3} \mathrm{SCD}$ ratio increases markedly from $<4.8 \times 10^{-6}$ to $>5.5 \times 10^{-6}$ for $\mathrm{NO}_{2}$ VCDs below $2 \times 10^{15}$ molec $\mathrm{cm}^{-2}$ at high solar zenith angles. This observation confirms the predictions of the simple model for stratospheric chemistry mentioned above. Normally, $\mathrm{NO}_{2}$ is a sink for stratospheric $\mathrm{BrO}$ leading to an anticorrelation between $\mathrm{BrO}$ and $\mathrm{NO}_{2}$. Therefore, the abundance of $\mathrm{BrO}$ is enhanced with respect to $\mathrm{O}_{3}$ at low $\mathrm{NO}_{2}$ concentrations.

The detailed steps of the partitioning algorithm are presented in Appendix A.

\subsection{Sensitivity filter and air-mass factor}

In order to finally retrieve the desired residual tropospheric $\mathrm{VCD}$ of $\mathrm{BrO}$ from the tropospheric SCD using

$V_{\text {trop }}=\frac{S_{\text {trop }}}{A_{\text {trop }}}$,

we need to calculate the tropospheric air-mass factor $A_{\text {trop}}$. This section describes how $A_{\text {trop }}$ can be retrieved from radiance measurements and $\mathrm{O}_{4} \mathrm{SCDs}$ and that each measurement can be classified into sensitive to the boundary layer (BL) and possibly obscured. The concentration of $\mathrm{O}_{4}$ is proportional to the square of the $\mathrm{O}_{2}$ concentration, and therefore its scale height is approximately $4 \mathrm{~km}$. Hence, its absorption is a good indicator for the photons having penetrated the lower part of the atmosphere (e.g. Wagner and Platt, 1998).

\subsubsection{Concept of the sensitivity filter}

Ground-based measurements showed that most of the enhanced tropospheric $\mathrm{BrO}$ column is located within the $\mathrm{BL}$
Table 3. Modelled layers of scattering media (aerosols and/or clouds) defined by their lower and upper edge over ground and the optical density (OD).

\begin{tabular}{cl}
\hline Layer $(\mathrm{km})$ & OD \\
\hline $0-1$ & $1,3,10,20,50$ \\
$1-2$ & $1,3,10,50$ \\
$3-4$ & 50 \\
$7-8$ & $1,3,10,50$ \\
\hline
\end{tabular}

and often close to the surface (e.g. Hönninger et al., 2004; Wagner et al., 2007; Pöhler et al., 2010; Prados-Roman et al., 2010; Frieß et al., 2011). We therefore assume, as an approximation, that the residual tropospheric column of $\mathrm{BrO}$ is entirely located between 0 and $500 \mathrm{~m}$ above the ground with a constant concentration (box profile). It is noted that the exact value of the $\mathrm{BrO}$ mixed layer-height may differ in reality. Radiative transfer simulations, however, showed that its choice is not critical for the presented considerations because the sensitivity of nadir measurements only slightly depends on altitude above surfaces with high albedo which are typical for polar regions. Therefore, instead of a real $\mathrm{AMF}_{\text {trop }}$, the AMF for the lowest $500 \mathrm{~m}\left(\mathrm{AMF}_{500}\right.$, denoted $\left.A_{500}\right)$ is retrieved and used in this work.

For nadir satellite observations, the sensitivity to the ground mostly depends on the surface albedo and whether clouds with a large cloud optical density (COD) are present. Under clear-sky conditions, the absorption signal from tracegases located close to the ground is reduced over dark surfaces due to little reflection by the ground compared to Rayleigh and Mie scattering in the atmosphere. But over bright surfaces, a substantial fraction of the observed photons penetrates near-surface layers. To a large extent, this is still true even for cloudy scenes. Thick clouds, however, effectively shield the absorption signal from these layers.

The distinction between sea ice, snow, thick aerosol layers, water clouds, and ice clouds by satellite remote sensing is not unambiguously possible (Vasilkov et al., 2010), and therefore surface albedo and COD cannot be readily derived from our measurements.

Instead, we chose an approach relying on proxies to parametrise $A_{500}$. The two proxies used in the proposed algorithm are the reflectance $R$ and the $\mathrm{O}_{4} \mathrm{AMF}, A_{\mathrm{O}}$. On the one hand, $R$ is a well suited measure to discriminate either clouds/ice (bright) and ocean/land (dark). $A_{\mathrm{O}}$, on the other hand, helps to discriminate between ice and clouds and furthermore provides information about the height and optical thickness of potential clouds. $R$ is calculated as

$R=\frac{L}{E}$

where $L$ and $E$ are the Earth radiance and solar irradiance measured by GOME- 2 at $372 \mathrm{~nm}$, respectively. The wavelength of $372 \mathrm{~nm}$ for $R$ was chosen in order to minimize 
(a)

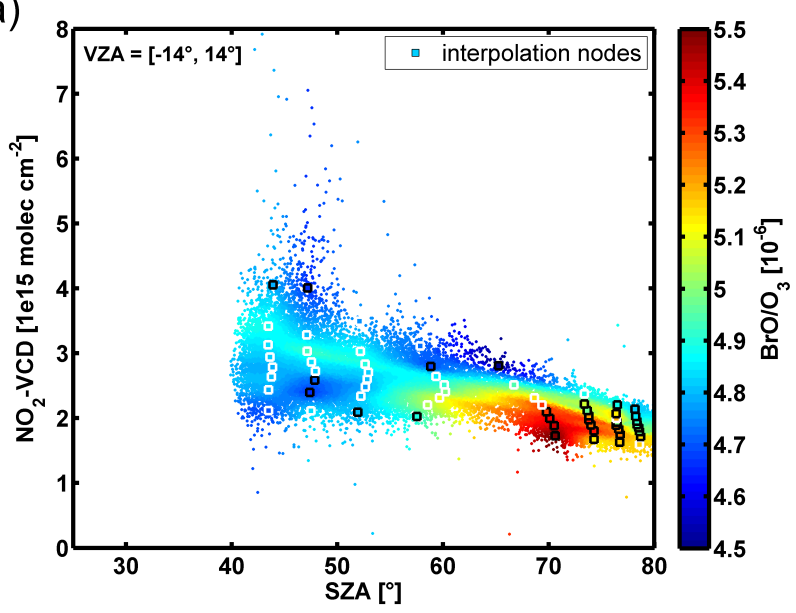

(b)

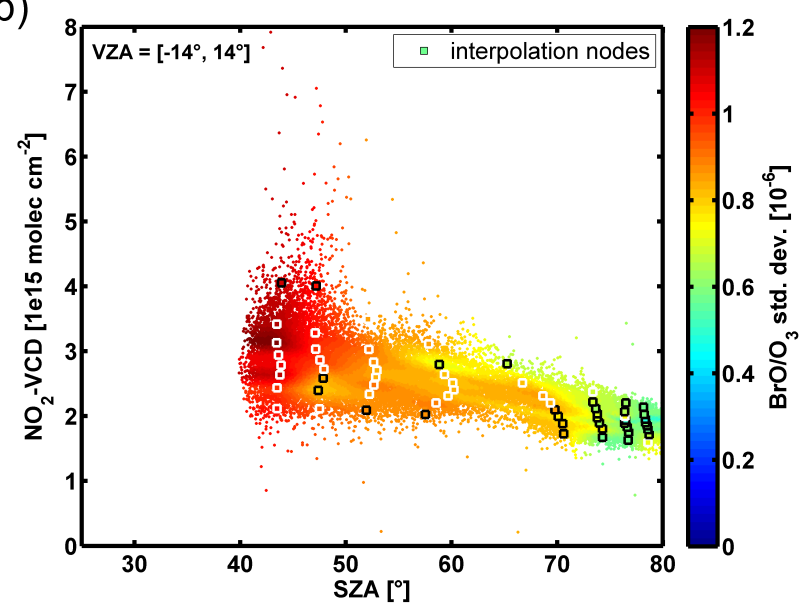

Fig. 5. Interpolation (a) of the $\mathrm{BrO} / \mathrm{O}_{3} \mathrm{SCD}$ ratio surface and (b) its standard deviation $\sigma$ depending on $\mathrm{SZA}$ and $\mathrm{NO}_{2} \mathrm{VCD}$. The nodes of the bilinear surface interpolation (squares) are the mean of the partitions displayed in Fig. 3. The distributions of some partition with a negligible asymmetry are not filtered before the interpolation and indicated by white squares.

interferences with trace-gases like $\mathrm{O}_{4}$ absorbing in the same range. $A_{\mathrm{O}}$ is calculated from the measured $\mathrm{O}_{4} \mathrm{SCD}, S_{\mathrm{O}_{4}}$, using

$A_{\mathrm{O}}=\frac{S_{\mathrm{O}_{4}}}{V_{\mathrm{O}_{4}}} \cdot 0.8$

where $V_{\mathrm{O}_{4}}=1.33 \times 10^{43} \mathrm{molec}^{2} \mathrm{~cm}^{-5}$ is the $\mathrm{O}_{4}$ VCD integrated from sea level to the top of the atmosphere. Equation (19) furthermore applies an empirical correction factor of 0.8 which has already been suggested by Wagner et al. (2009b) and Clémer et al. (2010) and was confirmed by sensitivity studies conducted for this work. The same definition is used for the computation of $A_{\mathrm{O}}$, and, hence, the reduction of the real $\mathrm{O}_{4} \mathrm{VCD}$ over an elevated surface cancels out in the comparison between measurement and model. However, the illustration in Fig. 6b depicts $A_{\mathrm{O}}$ measured on 25 March 2009 depending on the surface elevation.

Results from a computational radiative transfer model are used to study the interrelation between modelled values for $R, A_{\mathrm{O}}$ and $A_{500}$. For this purpose, triples of $\left(R, A_{\mathrm{O}}, A_{500}\right)$ were modelled for a comprehensive set of surface albedos and aerosol/cloud scenarios. The main objective in the next step is to identify the range (or area in the $\left(R, A_{\mathrm{O}}\right)$-plane) where $A_{500}$ exceeds a certain sensitivity threshold $\mathrm{AMF}_{500}^{\mathrm{min}}$. The range limits are geometrically approximated, parameterised, and saved in lookup tables (LUTs) for discrete viewing geometries. When finally analysing the measurements, the LUT parameters are interpolated depending on the viewing geometry. Whether a measurement fulfils the $\mathrm{AMF}_{500^{-}}^{\text {min }}$ criterion or not is then decided based on the measured $R$ and $A_{\mathrm{O}}$.

Finally, the AMF for the boundary layer $A_{500}^{\text {meas }}$ depends on $R$ and $A_{\mathrm{O}}$. The parameters $a_{0}, a_{x}$ and $a_{y}$ of the surface

$A_{500}^{\text {meas }}\left(R, A_{\mathrm{O}}\right)=a_{0}+a_{x} \cdot R+a_{y} \cdot A_{\mathrm{O}}$ are derived from a least-squares fit of a selection of modelled $\left(R, A_{\mathrm{O}}, A_{500}\right)$-triples with $A_{500}>\mathrm{AMF}_{500}^{\mathrm{min}}$. In analogy to the surface sensitivity algorithm, $a_{0}, a_{x}$ and $a_{y}$ are also stored in LUTs.

\subsubsection{Implementation of the sensitivity filter and AMF calculation}

This section describes the implementation of the surface sensitivity filter algorithm. For each viewing geometry, the algorithm consists of five steps: (i) modelling of $\left(R, A_{\mathrm{O}}, A_{500}\right)$ triplets for a fixed set of aerosol scenarios and surface albedos, (ii) interpolation of additional $\left(R, A_{\mathrm{O}}, A_{500}\right)$-triplets accounting for partial cloud cover and different surface scenarios, (iii) parameterisation of the range of the $\left(R, A_{\mathrm{O}}\right)$-plane where $A_{500}$ exceeds a given threshold $\mathrm{AMF}_{500}^{\min }$, (iv) derivation of the $a$-parameters in Eq. (20), and (v) allocation of derived parameters in lookup tables. The LUTs are finally needed to interpolate the stored parameters for each GOME2 pixel depending on its viewing geometry. The interpolated parameters are needed to decide whether a pixel is sensitive to the boundary layer and to calculate $A_{500}$ using Eq. (20).

There are four parameters defining the satellite viewing geometry: the SZA $\vartheta$, the solar relative azimuth angle (SRAA), the viewing zenith angle (VZA) $\psi$ and the ground elevation. These parameters span the four dimensional LUTs whose discretisation nodes are summarized in Table 2. Each LUT has a total of 6720 entries corresponding to 6720 different viewing geometries.

i. $R, A_{\mathrm{O}}$ and $A_{500}$ are modelled for different surface albedos and aerosol scenarios using the McArtim software package (Deutschmann et al., 2011). Two different wavelengths are used in the radiative transfer calculations: $R$ is derived from radiative transfer simulations at 

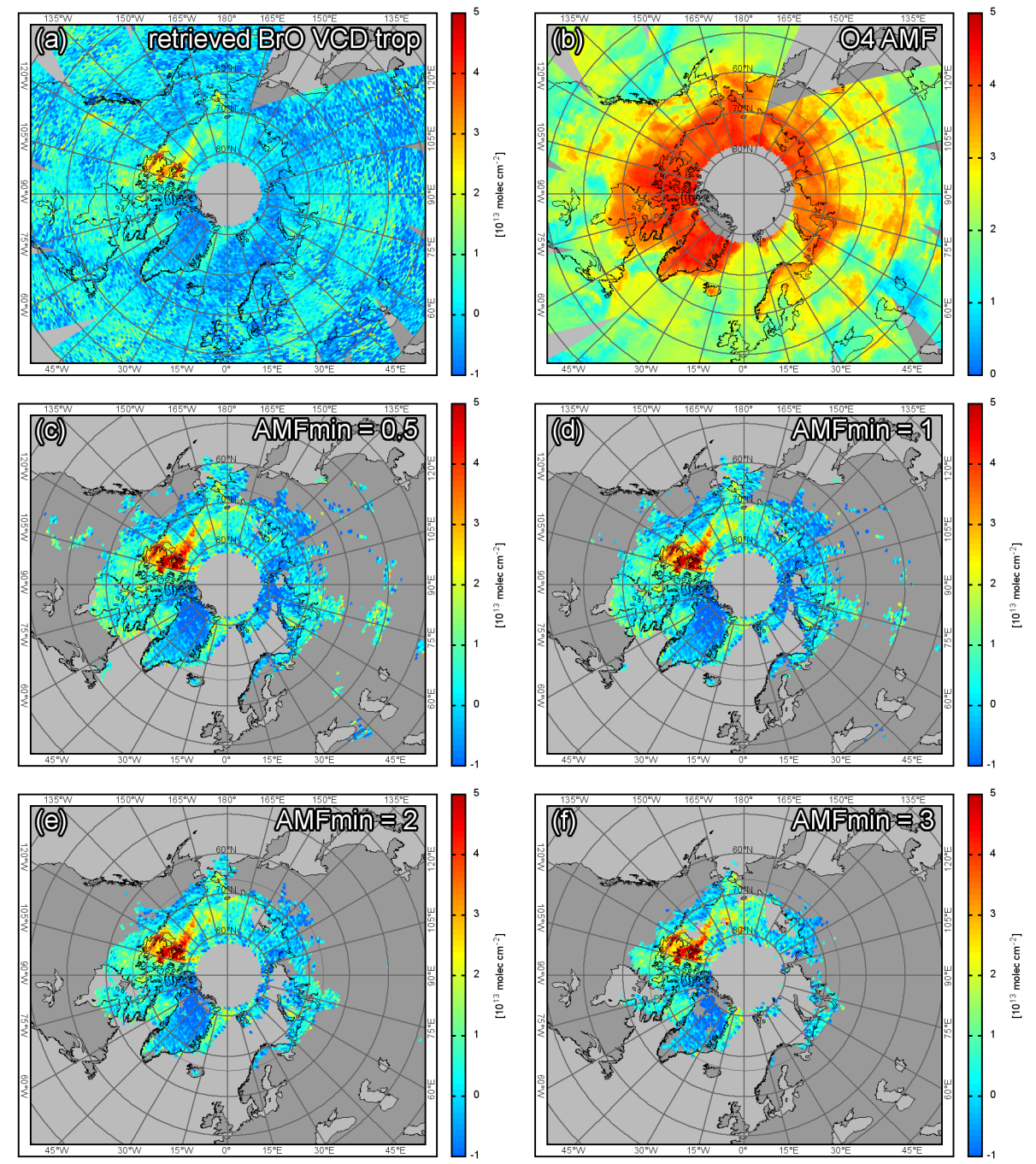

Fig. 6. Illustration of the sensitivity filter and tropospheric AMF applied on GOME-2 measurements for 25 March 2009 (same as Fig. 1). (a) The retrieved tropospheric BrO VCDs are filtered according to the respective minimum sensitivity to trace gas concentrations close to the surface using (b) measured AMFs of $\mathrm{O}_{4}$. Panels (c) through (f) show tropospheric BrO VCDs for different sensitivity thresholds $\mathrm{AMF}_{500}^{\min }=0.5,1,2,3$, respectively. Note that the sensitivity to the choice of $\mathrm{AMF}_{500}^{\mathrm{min}}$ is low. (a) is calculated using $A_{\mathrm{geom}}$; (c)-(f) are calculated using $A_{500}$. Areas without any sensitive measurements are left gray.

$372 \mathrm{~nm}$, whereas $A_{\mathrm{O}}$, and $A_{500}$ are simulated at $360 \mathrm{~nm}$. For each LUT entry, $R, A_{\mathrm{O}}$, and $A_{500}$ are calculated for the albedos $0.03,0.09,0.24,0.39,0.54,0.66,0.78,0.90$, 0.96 for a pure Rayleigh atmosphere (clear-sky) and the aerosol/cloud scenarios summarized in Table 3. For the calculation of $A_{500}$, a tropospheric box profile between 0 and $500 \mathrm{~m}$ is assumed.

Before the entire LUTs have been calculated, the scenarios summarised in Table 3 were found to be largely representative for the presented sensitivity filter through extensive radiative transfer simulations. However, two scenarios $(0-1 \mathrm{~km}$, OD 20 and $3-4 \mathrm{~km}$, OD 50) were added at a later stage in order to further improve the accuracy of the algorithm. It is noted that future studies may benefit from using even more selected scenarios yet increasing the computational cost of the algorithm.

ii. Further $\left(R, A_{\mathrm{O}}, A_{500}\right)$-triplets are interpolated from the Monte Carlo model results for two reasons: firstly, interpolation increases the number of values populating the $\left(R, A_{\mathrm{O}}\right)$-plane and hence increasing the accuracy of the subsequent parameterisation, and, secondly, it may be accounted for real gradients of surface albedo and partial cloud cover through interpolation. Large albedo gradients are typical for ice edges over oceans or areas of freshly fallen snow over land. Therefore, the surface albedo is parameterised by two properties: the albedo at a wavelength of $372 \mathrm{~nm}$ and the high albedo fraction of the surface $\eta_{\mathrm{s}}$. 
$\eta_{\mathrm{S}}$ is the geometric fraction of the ground pixel assumed to have a very high albedo $R_{\text {high }}=0.96$. The reflectance $R$ defined by Eq. (18) then depends on $\eta_{\mathrm{S}}$ and the modelled reflectances $R_{\text {high }}$ and $R_{\text {low }}$ over surfaces with an albedo of 0.96 and below 0.96 , respectively.

$R\left(\eta_{\mathrm{S}}\right)=\left(1-\eta_{\mathrm{S}}\right) R_{\text {low }}+\eta R_{\text {high }}$

The number of photons crossing the boundary between both parts is assumed to be negligible (independent pixel approximation). Accordingly, the modelled AMF depends on $\eta_{\mathrm{S}}$ following

$A\left(\eta_{\mathrm{S}}\right)=\frac{\left(1-\eta_{\mathrm{S}}\right) R_{\text {low }} A_{\text {low }}+\eta_{\mathrm{S}} R_{\text {high }} A_{\text {high }}}{\left(1-\eta_{\mathrm{S}}\right) R_{\text {low }}+\eta_{\mathrm{S}} R_{\text {high }}}$

where the modelled $A_{\text {low }}$ and $A_{\text {high }}$ are weighted by the modelled radiances (Martin et al., 2002).

Furthermore, scattering media in the atmosphere, i.e. clouds and/or aerosol layers, are modelled as a single layer with a geometric thickness of $1 \mathrm{~km}$ containing particles with a single scattering albedo of 1.00 and a Henyey-Greenstein asymmetry parameter of $g=0.85$ (King, 1987). The parametrization of scattering media in our model atmosphere has three dimensions: the cloud fraction $\left(\eta_{\mathrm{C}}\right)$, the cloud height $(\mathrm{CH})$ and the cloud optical density (COD). $\eta_{\mathrm{C}}$ is defined as the fraction of a scenery which is covered by clouds. In analogy to the definition of $\eta_{\mathrm{S}}$, photons are assumed to travel either through cloud-free (cf) or cloud-covered (cc) sceneries. The radiances and AMFs depending on the cloudfraction may then be interpolated using

$R\left(\eta_{\mathrm{c}}\right)=\left(1-\eta_{\mathrm{c}}\right) R_{\mathrm{cf}}+\eta_{\mathrm{c}} R_{\mathrm{cc}}$

and

$A\left(\eta_{\mathrm{c}}\right)=\frac{\left(1-\eta_{\mathrm{c}}\right) R_{\mathrm{cf}} A_{\mathrm{cf}}+\eta_{\mathrm{c}} R_{\mathrm{cc}} A_{\mathrm{cc}}}{\left(1-\eta_{\mathrm{c}}\right) R_{\mathrm{cf}}+\eta_{\mathrm{c}} R_{\mathrm{cc}}}$

respectively.

Summing up the interpolation steps for the radiance and both AMFs for fractional $\eta_{\mathrm{S}}$ and COD, (1) $\eta_{\mathrm{C}}$ is varied from 0.2 to 0.8 for every constant albedo using Eqs. (23) and (24), respectively. (2) For the clear-sky case, $\eta_{\mathrm{S}}$ ranges from 0.05 to 0.95 with steps of 0.05 using Eqs. (21) and (22), respectively. (3) With clouds, $\eta_{\mathrm{S}}$ and $\eta_{\mathrm{c}}$ were varied from 0 to 1 and from 0.2 to 1 , respectively, both with steps of 0.2 . This scheme results in 938 modelled and interpolated $\left(R, A_{\mathrm{O}}, A_{500}\right)$-triplets. As an example, all triplets are shown in Fig. 7a for a nadir looking geometry and $\mathrm{SZA}=76^{\circ} . R$ is plotted along the abscissa-axis, and $A_{\mathrm{O}}$ is plotted along the ordinate-axis. $A_{500}$ values are colour-coded. The comparison between modelled and measured $\left(R, A_{\mathrm{O}}\right)$-pairs in Fig. $7 \mathrm{~b}$ shows that the range of modelled values (for a specific viewing geometry) includes almost all corresponding measurements. Obviously, the numerical radiative transfer model McArtim is capable of reproducing the range of real measurements for the considered cloud scenarios.

Figure 7 furthermore illustrates the advantages of using the two parameters $R$ and $A_{\mathrm{O}}$ instead of using just a single $A_{\mathrm{O}}$ threshold. There is a significant number of measurements located in the sensitive range featuring an $\mathrm{O}_{4} \mathrm{AMF}$ below point $\mathrm{A}$ but also at a lower radiance. These measurements would be lost if only one threshold criterion based on $S_{\mathrm{O}_{4}}$ was applied. Furthermore, the measurements gained from using the two-parameter approach are particularly precious for the investigation of bromine activation in the Arctic. These measurements are more likely located at the sea-ice edge, because, at a given radiance $R, A_{\mathrm{O}}$ is maximal for clear-sky scenarios over pixels partially covered by sea ice.

iii. The limits of range $P$ in the $\left(R, A_{\mathrm{O}}\right)$-plane containing $A_{500}$-values smaller than $\mathrm{AMF}_{500}^{\text {min }}$ are parameterised. $P$ is the inverse of the range where an $A_{500}$ exceeding $\mathrm{AMF}_{500}^{\mathrm{min}}$ can be assured. The limits of $P$ are geometrically approximated in order to obtain a suitable parameterisation. Therefore, a convex hull $H$ containing all $A_{500}$ smaller than $\mathrm{AMF}_{500}^{\mathrm{min}}$ is constructed.

As depicted by the shaded area in Fig. 7a, the characteristic shape of $H$ enables us to approximate its upper edge with a parabola $g$ :

$g(R)=g_{0}+g_{1} R+g_{2} R^{2}$.

Before $g$ is approximated to the upper edge of $H$, we introduce an intensity threshold $h$. Using the reflectances of the upper right corner $A$ and left corner $B$ of $H, R_{A}$ and $R_{B}$, respectively, $h$ is given by the mean

$h=\left(R_{A}+R_{B}\right) / 2$.

Finalizing the parameterisation of the edge, $g$ is derived from a least-squares fit using the points of the upper edge of $H$ with $R \geq h$.

iv. A least-squares surface fit of all modelled and interpolated triples in the upper right section (greater than $g$, and $h$ ) is performed using the model function in Eq. (20). Figure 8 compares $A_{500}$ resulting from the bilinear model to the modelled and interpolated input values of the fit for one example geometry $\left(\mathrm{SZA}=76^{\circ}\right.$, same as in Fig. 7). This plot reveals that a single value (mean or median) would add a significant systematic error to the retrieved $A_{500}$ compared to the real $A_{500}$. It is therefore concluded that using the two proxies ( $R$ and $A_{\mathrm{O}}$ ) for the determination of $A_{500}$ offers the opportunity to even quantify $A_{500}$ to some degree instead of e.g. using a constant value. 
(a)

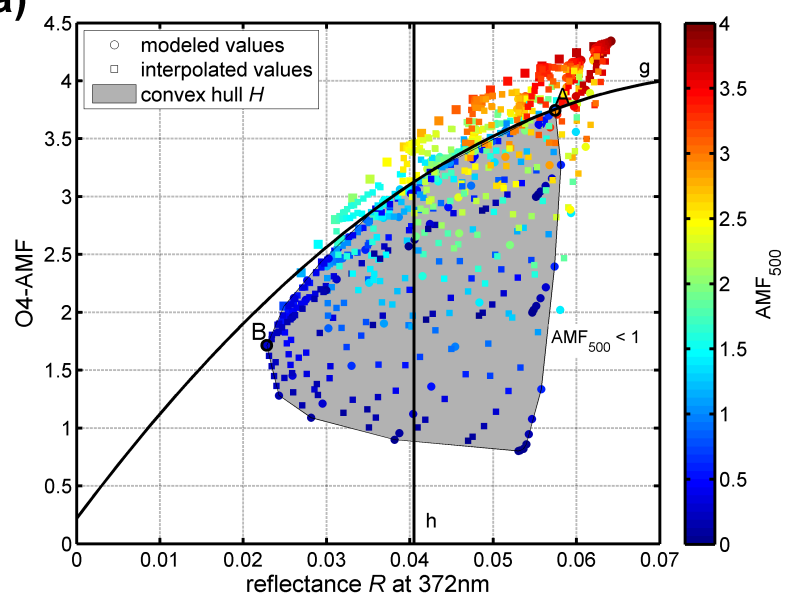

(b)

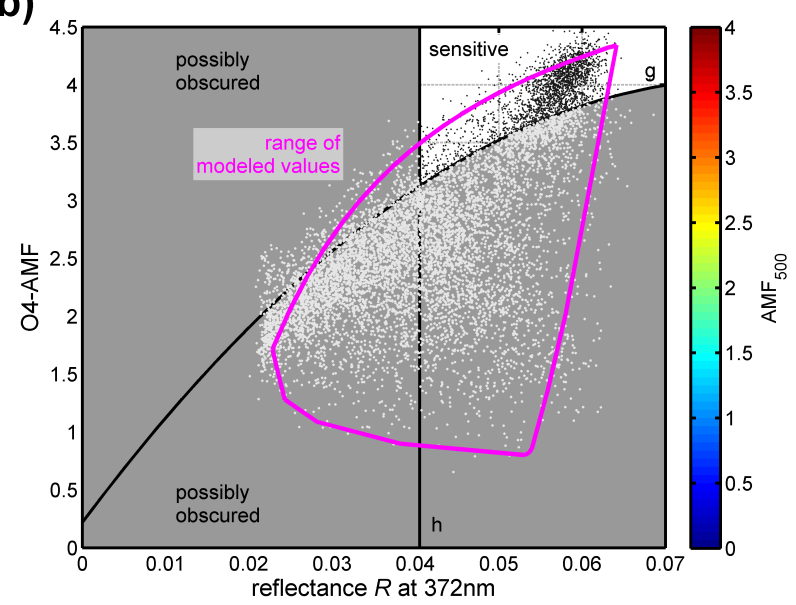

Fig. 7. (a) Modelled and interpolated $\left(R, A_{\mathrm{O}}, A_{500}\right)$-triplets for a nadir geometry at $\mathrm{SZA}=76^{\circ}$. The convex hull $H$ (shaded area) including all $A_{500}<1=\mathrm{AMF}_{500}^{\mathrm{min}}$ is parameterised in order to provide a threshold for the surface sensitivity filter. (b) Classification of all GOME-2 nadir observations of 2008 at the same SZA based on measured $R$ and $A_{\mathrm{O}}$ with a threshold of $\mathrm{AMF}_{500}^{\min }=1$. The described filter distinguishes between measurements sensitive to the lowest $500 \mathrm{~m}$ of the atmosphere (black dots) and those that are possibly obscured by clouds and/or too low albedo (grey area, bright dots). The convex hull (magenta) of modelled values contains approx. $88 \%$ of the measurements.

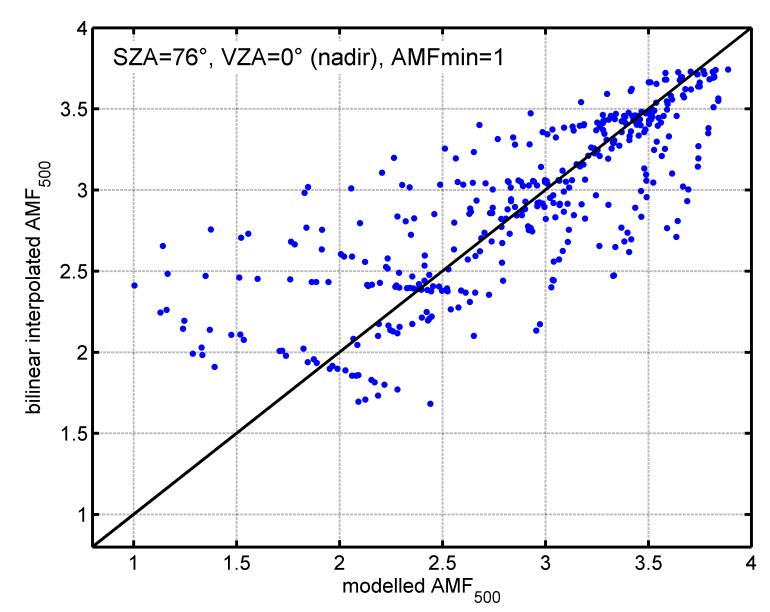

Fig. 8. Comparison between modelled/interpolated values for $A_{500}$ and values interpolated from the parametrisation at a fixed nadir geometry of $\mathrm{SZA}=76^{\circ}$ and a threshold of $\mathrm{AMF}_{500}^{\mathrm{min}}=1$ (same as in Fig. 7).

v. For a given $\mathrm{AMF}_{500}^{\text {min }}, h, g_{0}, g_{1}, g_{2}$ and the surface fit parameters $a_{0}, a_{x}$ and $a_{y}$ are stored in seven separate LUTs, which are then used to interpolate the thresholds and $\mathrm{AMF}_{500}^{\text {meas }}$ for any observation geometry for any measured $R$ and $A_{\mathrm{O}}$.

Finally, an observation is flagged as sensitive if $A_{\mathrm{O}}$ and $R$ are larger than $g$ and $h$, respectively, or otherwise as possibly obscured. If the measurement is sensitive, $A_{500}$ is derived using interpolated values for $a_{0}, a_{x}$ and $a_{y}$.

\subsection{Results and discussion of the retrieval algorithm}

Tropospheric VCDs of BrO resulting from the column separation algorithm are displayed for 25 March 2009 in Fig. 1e and for 1 April 2007 in Fig. 2e. Both figures illustrate the capability of the algorithm to separate the residual tropospheric column from the measured total column and to reduce the correlation to the tropopause height on a large scale. Fine-structured areas of elevated $\mathrm{BrO}$ remain in the retrieved tropospheric columns. For 1 April 2007, the pixels in the east sector fall into areas where the $\mathrm{O}_{3}$ VCDs are reduced due to ozone hole conditions. These are removed from the retrieval.

Figure 6 shows the tropospheric BrO columns for different choices of the $\mathrm{AMF}_{500}^{\mathrm{min}}$ threshold. The algorithm successfully removes measurements over areas outside the Arctic with a relatively low surface albedo. The comparison between Fig. 6c through $6 \mathrm{f}$ shows that the maps depend only slightly on the choice of $\mathrm{AMF}_{500}^{\mathrm{min}}$.

It is important to note that the presented algorithm - compared to previously published algorithms - depends neither on results from stratospheric chemistry models, gridded measurements from other satellite instruments nor surface albedo climatologies avoiding the disadvantages of using a potentially biased model description and possible short-term deviations from climatological values. Apart from the potential vorticity data provided by ECMWF to identify areas potentially disturbed by ozone hole chemistry, only data measured by the GOME- 2 instrument are required.

Another distinct advantage of the column separation algorithm is that measurement errors are derived based on observations and not based on the mathematical fit error of 
the SCD retrieval. As pointed out by Stutz and Platt (1996), the fit error may underestimate the true error in the presence of erroneous reference cross-section alignment and systematically structured residual spectra. However, these malicious influences are difficult to quantify. In this work, empirically derived measurement errors are derived in order to provide a realistic error estimation which also includes the error of the column separation. Hence, it is possible to decide whether a measured $\mathrm{BrO}$ column density significantly exceeds the stratospheric background in the SCD space. This can be particularly advantageous when calculating the correlation to independent data sources by avoiding a systematic bias from potentially flawed assumptions of the vertical distribution and the state of the atmosphere, which are necessary to solve the radiative transfer.

\section{Validation}

The last section described the methods of a new satellite retrieval for tropospheric $\mathrm{BrO}$ column densities. Several parameters of the implementation to separate the tropospheric from the total column and the sensitivity filter algorithm for the boundary layer were determined by numerical inspection. The algorithm proved to be stable, and varying the different parameters within reasonable limits resulted in minor variations of the result. Due to its complexity, however, it is especially important to validate the presented algorithm in order to unravel potential flaws.

A validation requires independent measurements. Unfortunately, for tropospheric $\mathrm{BrO}$ columns, there is no independent satellite data to compare with and therefore the different steps of the algorithm are validated separately using either simulated data or measurements from instruments other than GOME-2: (1) the decomposition algorithm of the total $\mathrm{BrO}$ column is tested on simulated measurements (Sect. 3.1) and (2) using concentration profiles of $\mathrm{BrO}, \mathrm{O}_{3}$ and $\mathrm{NO}_{2}$ provided by atmospheric chemistry model simulations (Sect. 3.2). (3) Results of the surface sensitivity filter are validated through a case study of imaging satellite data in the red spectral region (Sect. 3.3) and (4) compared to optical properties of clouds measured by the CALIOP instrument (Sect. 3.4). (5) The comparison of retrieved tropospheric VCDs to ground-based measurements of $\mathrm{BrO}$ is described in Sect. 4. It is noted that cross-validations to airborne DOAS measurements have already been published in Prados-Roman et al. (2010) and Heue et al. (2011).

\subsection{Proof of concept of column separation algorithm using simulated measurements}

In Sect. 2.2 we presented an algorithm to retrieve the ratio of stratospheric SCDs of $\mathrm{BrO}$ and $\mathrm{O}_{3}$. The algorithm mainly consists of a two-dimensional partitioning of the measurements (Appendix A) and an asymmetry filter. Here, the capability of the algorithm to retrieve the true $\bar{z}_{0}\left(\vartheta, V_{\mathrm{N}}\right)$ is benchmarked.

As a matter of fact, the true $\bar{z}_{0}$ is not known for the satellite nadir geometry. Therefore, the whole numerical algorithm is benchmarked using simulated measurements instead. The simulations are based on mathematical distributions without any a priori chemistry or radiative transfer. The retrieved $\bar{z}_{0}$ may then be compared to the known model function $z_{m}$ used as an input for the measurement simulation.

Within the domain defined in Eq. (A2), we choose the surface

$z_{m}: z=a \hat{x} \cos \hat{y}+b$

with the normalised coordinates $\hat{x}=\left(\vartheta-25^{\circ}\right) / 55^{\circ}$ and $\hat{y}=$ $V_{\mathrm{N}} /\left(8 \times 10^{15}\right.$ molec $\left.^{-2}\right)$ to model the stratospheric response of $\mathrm{BrO} / \mathrm{O}_{3} \mathrm{SCD}$ ratio measurements (Fig. 9a). The parameters in Eq. (27) are $a=5 \times 10^{-7}$ and $b=4.9 \times$ $10^{-6}$, respectively. Then, $2 \times 10^{4}$ measurements of $\left(\vartheta, V_{\mathrm{N}}, z\right)$ triplets are simulated to sample $z_{m}$ using several randomnumber generators.

The $\left(\vartheta, V_{\mathrm{N}}\right)$-plane is populated by two normal distributions as displayed in Fig. 9b. Then, for each $(\hat{x}, \hat{y})$-pair, a normally distributed "tropospheric" value centred around 0 with a standard deviation $\sigma_{z, 1}=0.4 \times 10^{-7}$ is added to the respective value of $z_{m}$. Additionally, normally distributed values $\left(\sigma_{z, 2}=1.5 \times 10^{-6}\right.$, offset $\left.\Delta z_{2}=1.5 \times 10^{-6}\right)$ are added to $15 \%$ of the measurements to model events of enhanced $\mathrm{BrO} / \mathrm{O}_{3}$-fractions. As an example, the resulting distribution of $z$ of measurements falling within the interval centred at $\vartheta=70.9^{\circ}$ and $V_{\mathrm{N}}=2.2 \times 10^{15} \mathrm{molec} \mathrm{cm}^{-2}$ is shown in Fig. 9d.

After the generation of measurements, the algorithm to derive $\mathrm{BrO} / \mathrm{O}_{3}$-fractions is applied as described in Sect. 2.2. The results are compiled in Fig. 9 with axes similar to Figs. 3, 4, and 5, respectively. The differences between $z_{m}$ and the retrieved surface $\bar{z}_{0}$ and the relative error $\sigma_{0}$ are illustrated in Fig. 9e and f, respectively. Both plots show that the algorithm succeeds in reproducing the model function within the sampled area. Residual linear structures of the difference are artefacts caused by the bilinear interpolation between the nodes of retrieved surface. The relative error almost never $(<1 \%)$ exceeds $2 \%$, and the relative mean error is $0.5 \%$.

In conclusion, the presented algorithm is capable of reproducing a given model surface for the stratospheric $\mathrm{BrO} / \mathrm{O}_{3}$ SCD ratio within the sampled area. The described simulator was used to test different combinations of parameters for the algorithm (number of nodes, partitioning scheme, interpolation method, convergence thresholds). The final implementation of parameters was found to provide a reasonable trade-off between resolution and sampling error. 
(a)

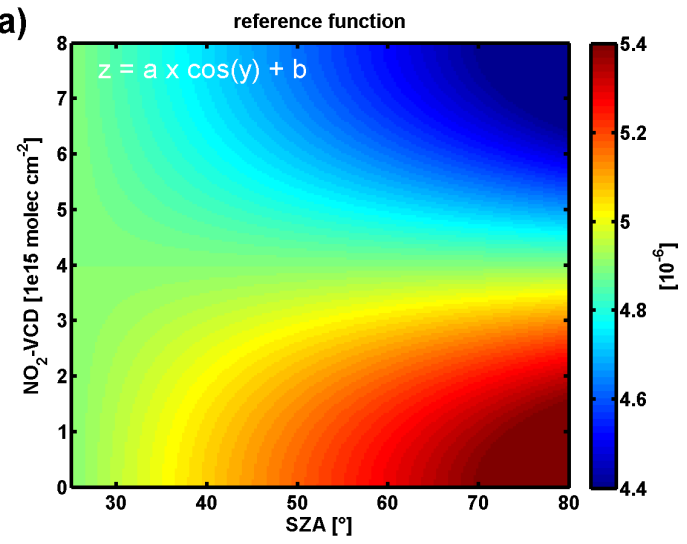

(c)

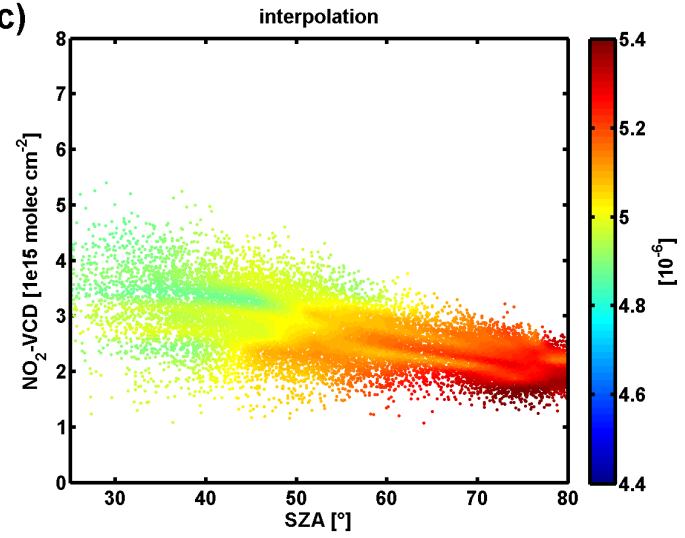

(e)

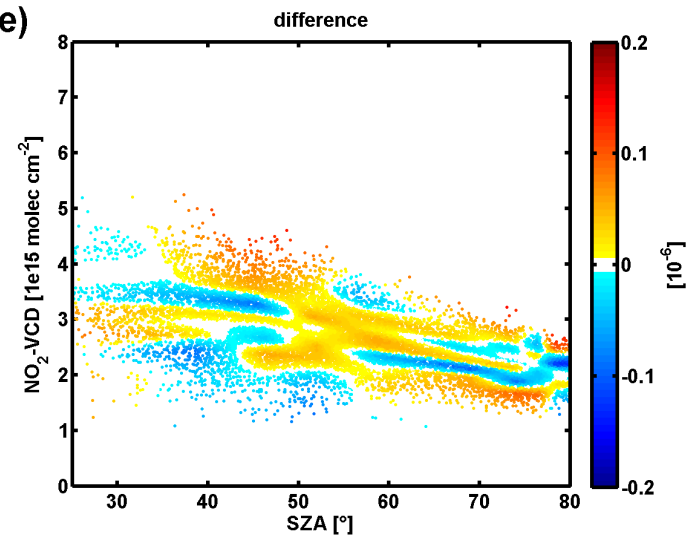

(b)

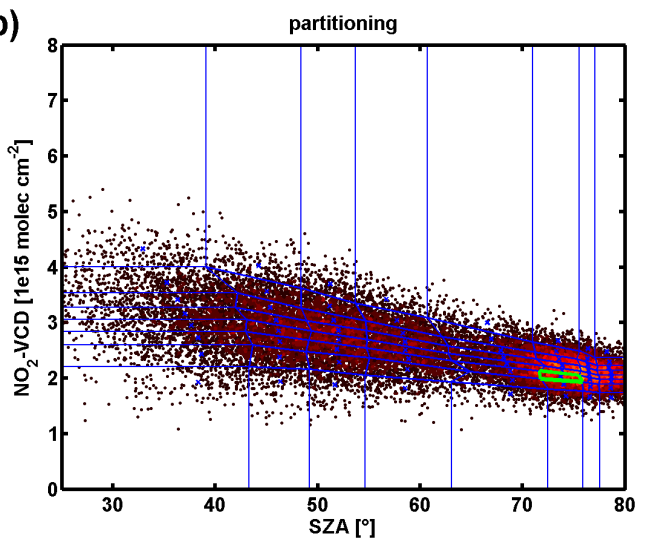

(d)

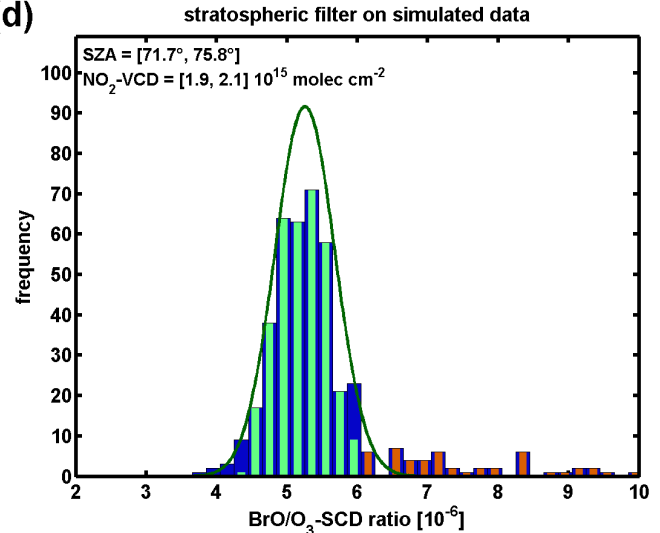

(f)

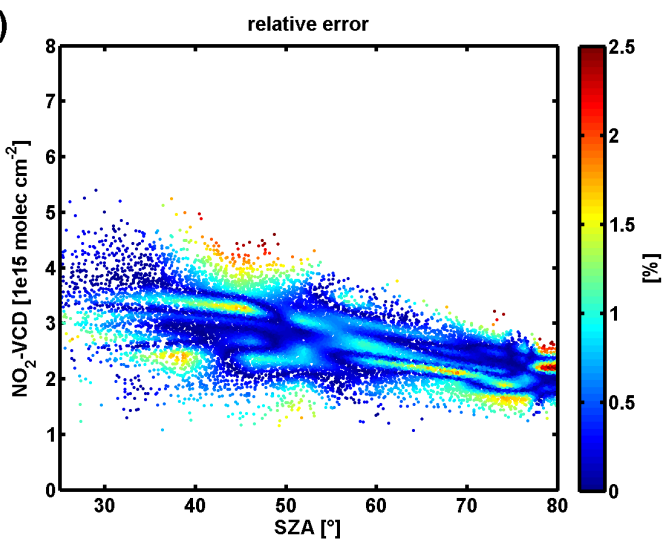

Fig. 9. Benchmark of the separation algorithm (Sect. 2.2 and Appendix A) using simulated measurements modelling a (a) known surface. (b) Partitioning of measurements, (c) interpolated surface nodes, (d) application of asymmetry filter. (e) The difference between true and retrieved surface function shows only small deviations. (f) The relative error almost never exceeds $2 \%$.

\subsection{Proof of concept of column separation algorithm using profiles simulated by EMAC}

In addition to simulated measurements, it is also possible to benchmark the proposed column separation algorithm applying concentration profiles of $\mathrm{BrO}, \mathrm{O}_{3}$, and $\mathrm{NO}_{2}$ simulated by a chemistry climate model (CCM). SCDs of $\mathrm{BrO}$ and $\mathrm{O}_{3}$ as well as VCDs of $\mathrm{NO}_{2}$ are computed from an ensemble of profile triplets provided by the CCM and using radiative transfer calculations. Then, the algorithm presented in Sect. 2.2 is applied on the computed SCDs and VCDs in order to retrieve again the stratospheric BrO SCDs. These $\mathrm{BrO}$ SCDs are compared to the original BrO SCDs and, hence, benchmarked. This approach is presented here and has two distinct advantages compared to the study in Sect. 3.1: it incorporates radiative transfer effects which may lead to deviations due to differences in the concentration profiles, and the ensemble of computed values should be more realistic. 
(a)

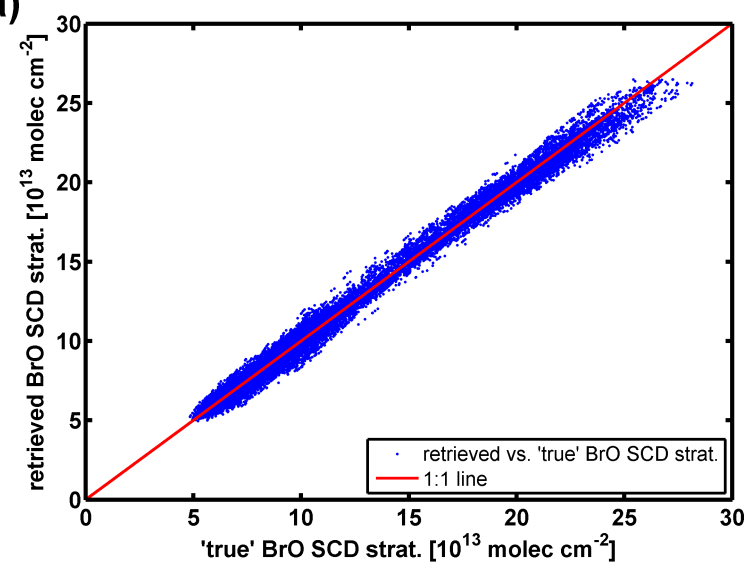

(b)

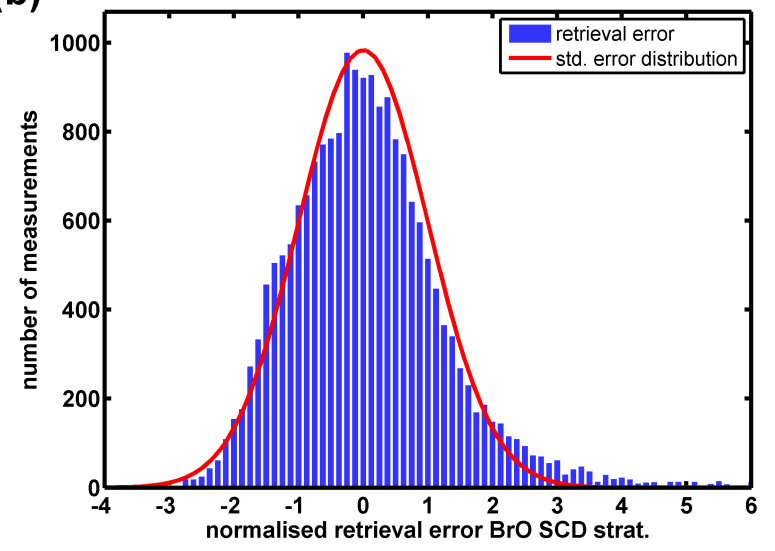

Fig. 10. Benchmark results of the column separation algorithm using an ensemble $(n=20000)$ of concentration profiles of $\mathrm{BrO}$, $\mathrm{O}_{3}$, and $\mathrm{NO}_{2}$ simulated by the EMAC model. (a) Retrieved stratospheric BrO SCDs against "true" input BrO SCD. (b) Distribution of the difference between retrieved and input $\mathrm{BrO}$ SCD normalised by the $\mathrm{BrO}$ standard deviation $\sigma_{\text {strat }}$ as provided by the retrieval (see text).

Table 4. Differences between CALIOP/CALIPSO and the GOME2/MetOp-A.

\begin{tabular}{lll}
\hline & CALIOP/CALIPSO & GOME-2/MetOp-A \\
\hline Footprint & $70 \mathrm{~m}$ diameter & $80 \times 40 \mathrm{~km}^{2}$ \\
Swath-width & - & $1920 \mathrm{~km}$ \\
Equator crossing & $13: 30 \mathrm{LT}$ & $09: 30 \mathrm{LT}$ \\
Flight altitude & $705 \mathrm{~km}$ & $817 \mathrm{~km}$ \\
Orbital period & $99 \mathrm{~min}$ & $101 \mathrm{~min}$ \\
Inclination & $98.2^{\circ}$ & $98.7^{\circ}$ \\
\hline
\end{tabular}

The data basis for this study is concentration profiles of $\mathrm{BrO}, \mathrm{O}_{3}$ and $\mathrm{NO}_{2}$ which were computed by the ECHAM5/MESSy Atmospheric Chemistry (EMAC) model described by Jöckel et al. (2010). This model, of which the results of a "nudged" (towards ECMWF analysis data) simulation in T42L90MA resolution are used, incorporates the Modular Earth Submodel System (MESSy) in the ECHAM5 global climate model (GCM) developed by the MPI for Meteorology, Hamburg. One distinct feature of the EMAC output is provided by the SORBIT submodel, which saves the result at the overpass times and locations of sun-synchronous satellite instruments like GOME-2 (Jöckel et al., 2010). Therefore, compared to the application of typical model output (global snapshots), a higher correlation between model and satellite measurement can be expected. It is noted that the output of EMAC used here features only a resolution of 128 times 64 grid cells in longitudinal and latitudinal direction, respectively. Therefore, model data of seven consecutive days between 22 and 28 March 2007 are used in order to increase the total number of different concentration profiles. The model profiles are filtered applying the same selection criteria as to the measurements (Sect. 2.2.2).
An ensemble of $n=20000$ simulated satellite measurements of $\mathrm{BrO}, \mathrm{O}_{3}$ and $\mathrm{NO}_{2}$ is generated from the EMAC profiles. $n$ is similar to the typical number of measurements in one $\psi$-range. Hence, the choice of $n$ is reasonable because only nadir measurements are considered here for the sake of simplicity. A random concentration between 10 and $40 \mathrm{ppt}$ is added to the lowest $500 \mathrm{~m}$ of $50 \%$ of the randomized $\mathrm{BrO}$ profiles in order to simulate events of enhanced near-surface $\mathrm{BrO}$. From these profiles, the total SCDs of $\mathrm{BrO}$ and $\mathrm{O}_{3}$ are computed using again the McArtim model applying a pure Rayleigh atmosphere without any aerosols and clouds, a random surface albedo between $3 \%$ and $96 \%$, and the respective SZA of the profile. The computation of the $\mathrm{NO}_{2} \mathrm{VCD}$ is trivial. Finally, the column separation algorithm is applied on the simulated column measurements in order to retrieve a stratospheric BrO SCD $S_{\text {strat }}$ and its standard deviation $\sigma_{\text {strat }}$ according to Eqs. (15) and (16), respectively.

Figure 10a correlates the retrieved $S_{\text {strat }}$ to the "true" stratospheric $\mathrm{BrO} \mathrm{SCD} S_{\mathrm{strat}}^{*}$ without the random tropospheric $\mathrm{BrO}$ enhancement. An almost perfect correlation $\left(r^{2}=0.99\right)$ is found between $S_{\text {strat }}$ and $S_{\text {strat }}^{*}$. The deviation of the slope (not shown) from the 1 to 1 line is of the order of the numerical error. Hence, it can be concluded that the proposed algorithm succeeded in retrieving the correct stratospheric BrO SCD with negligible systematic bias. This finding is particularly important because it indicates that the requirement of the column separation algorithm for sufficiently similar vertical profiles of $\mathrm{BrO}$ and $\mathrm{O}_{3}$ is probably also fulfilled in reality. In reality, however, additional interferences due to clouds and more complex structures of the surface albedo may arise potentially decreasing the correlation.

Finally in this study, the differences between the retrieved and original BrO SCD $\Delta_{\text {strat }}=S_{\text {strat }}^{*}-S_{\text {strat }}$ are compared to the $\sigma_{\text {strat }}$ as provided by the retrieval. Figure $10 \mathrm{~b}$ shows 
the distribution of the $\Delta_{\text {strat }}$ divided by the retrieved $\sigma_{\text {strat }}$. The red line is the normal probability density function with a standard deviation of unity. The agreement between the retrieved distribution and the model assumptions for normally distributed data is remarkable. Despite the small asymmetry, this figure demonstrates that the error computed by the proposed retrieval is a realistic estimate for the real measurement error of the separated stratospheric BrO SCD.

\subsection{Comparison to AVHRR image data}

As described in Sect. 2.3, the sensitivity of GOME-2 measurements to surface near trace-gas concentrations is difficult to quantify over sea-ice and snow-covered land due to ambiguities in the optical properties of the surface (ice/snow) and clouds (water/ice). However, by comparing the results of the presented sensitivity algorithm to AVHRR reflectance measurements, it is possible to test the general response of the algorithm towards the shielding effect of (A) thin clouds over a dark lead, (B) thick clouds over ice, and (C) over only partially snow-covered land (Fig. 11).

The AVHRR/3 instrument is also borne by the MetOpA satellite and measures reflectances at five spectral bands between the visible red and the thermal infra-red spectral range at a spatial resolution of $1.1 \mathrm{~km}$. The black-and-white image in Fig. 11 shows AVHRR reflectance measurements at $630 \mathrm{~nm}$ (channel 1) of Northern Alaska and the Arctic Ocean from 4 April 2009 at 22:43:42 UTC. The scenery is dominated by large bright areas of sea ice in the Bering Strait, the Arctic Ocean, as well as snow between the northern coast of Alaska and the Brooks Range in the south. The colour-coded outlines of individual satellite pixels represent pixels assured to be sensitive to the surface with $\mathrm{AMF}_{500}^{\mathrm{min}}=3$.

While the center of the satellite swath features the highest $A_{500}$ (dark red pixels in the upper part), the algorithm manages to detect regions with a reduced sensitivity to the surface. Clearly, the sensitivity to the surface is reduced over dark surfaces like (A) the Barrow lead at the north-west coast of Alaska and (C) over the darker slopes of the Brooks Range to the bottom of the figure. A little bit more subtle (B) is the shielding effect of clouds in the east. The linear cracklike features in the sea ice are almost completely blurred by clouds which can be identified by their shadows towards the north-west.

\subsection{Comparison to CALIPSO cloud data}

In order to validate the selectivity and response of the presented sensitivity filter (Sect. 2.3) towards clouds over bright surfaces, filter results are compared to measurements of the Cloud-Aerosol Lidar with Orthogonal Polarization (CALIOP) instrument. CALIOP is an active instrument measuring the time-resolved backscatter signal of a pulsed laser beam from which, among other parameters, the height and optical density of clouds may be derived independently

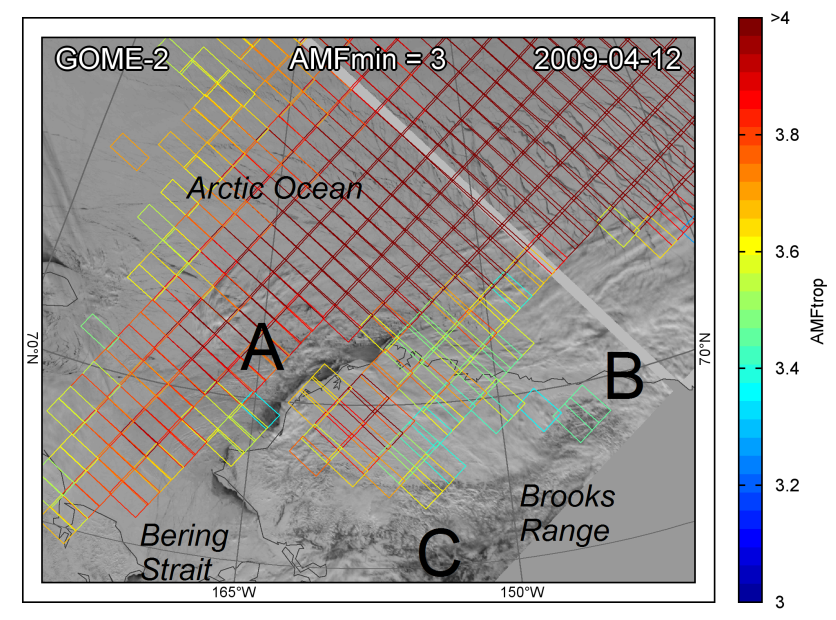

Fig. 11. Overlying image of derived $A_{500}$ (colour-coded) and AVHRR reflectance measurements (monochrome background, channel 1, $630 \mathrm{~nm}$ ) over Northern Alaska and the Arctic Ocean. Blue quadrangles indicate GOME-2 satellite pixels with an assured sensitivity to near-surface absorbers $\left(A_{500} \geq 3\right)$. Pixels above leads at the north-west coast of Alaska (A), above clouds (B), and over the dark Brooks Range $(\mathrm{C})$ are labelled possibly obscured $\left(A_{500}<3\right)$ and not plotted.

from the surface albedo (NASA, 2006; Winker et al., 2007). CALIOP is the primary instrument carried by the Cloud-Aerosol Lidar and Infrared Pathfinder Satellite Observations (CALIPSO) satellite.

The specification of the satellites MetOp-A and CALIPSO and the measuring principle of the respective GOME-2 and CALIOP instruments differ fundamentally (see Table 4). The most dominant difference is the footprint of each instrument. CALIOP samples a single 70-m-wide cross-section of the atmosphere while GOME-2 averages over $3200 \mathrm{~km}^{2}$. CALIOP thus only probes $0.2 \%$ of the atmospheric area within one GOME-2 pixel at most. A one-to-one comparison of GOME2 and CALIOP measurements is therefore problematic, but it is still possible to compare averages assuming the cloud properties CALIOP measures are to some extent representative for the whole GOME-2 pixel. Furthermore, CALIPSO flies on different orbit than MetOp-A. CALIPSO crosses the Equator around 13:30LT in ascending node while MetOpA has an Equator crossing time of 09:30 LT in descending node. In polar regions, however, the orbits of both satellites partly overlap. The time difference between a CALIPSO and a MetOp-A overpass varies periodically and there are chances for almost simultaneous measurements.

In this study, four years of provisional CALIPSO Lidar Level $25 \mathrm{~km}$ cloud layer data are compared to the classification of GOME-2 pixels regarding the sensitivity to the surface (Sect. 2.3). The comparison focuses on the ability of the algorithm to detect clouds over bright surfaces possibly reducing the sensitivity to trace-gases at the surface. Therefore, only pixels featuring a high sea-ice concentration of $95 \%$ are 
considered here. Sea-ice concentration maps derived from microwave-radar measurements were provided by the Integrated Climate Data Center (ICDC); see Kaleschke et al. (2001) and Spreen et al. (2008) for a detailed description of the product. Additionally, only measurements in the Northern Hemisphere below $83^{\circ} \mathrm{N}$ latitude are compared. The time difference between both measurements is limited to $30 \mathrm{~min}$, and every GOME-2 pixel taken into account must contain at least $70 \mathrm{~km}$ of the CALIPSO ground-track. Finally, 15374 collocated measurements meet these selection criteria in the months February to June of the years 2007 to 2010.

Depending on $\mathrm{AMF}_{500}^{\min }$, two properties of the CALIPSO data set, the cloud optical thickness (COT) and layer top altitude (LTA) of the uppermost layer, are selected, averaged and classified following the sensitivity algorithm applied on the specific GOME-2 pixel they are collocated with. Figure 12 shows the comparison between the surface sensitivity filter, retrieved $A_{500}$ and collocated CALIPSO measurements. The comparison to COT (Fig. 12, left column) is discussed first and followed by the comparison to LTA (Fig. 12, right column).

The histogram in Fig. 12a shows the distribution of all collocated measurements compared to measurements classified as possibly obscured by the sensitivity filter for different thresholds $\mathrm{AMF}_{500}^{\mathrm{min}}=0.5, \ldots, 3.5$. There are two accumulation points: one for COT $<1$ and another between 3 and 3.5 COT. The first accumulation point is due to essentially cloudfree pixels, and the second one is probably caused by clouds that are optically thicker than can be resolved by CALIOP leading to a systematic underestimation for these clouds. For increasing $\mathrm{AMF}_{500}^{\mathrm{min}}$, however, an increasing percentage of measurements are flagged as possibly obscured which is also shown in Fig. 12c. Figure 12c furthermore illustrates that the percentage of flagged measurements increases with increasing COT and the choice of $\mathrm{AMF}_{500}^{\min }$ as expected. Hence, it may be concluded that the proposed surface sensitivity filter is COT selective over sea ice and able to classify the majority of pixels with high COT as possibly obscured. The dependence of $A_{500}$ on COT plotted in Fig. 12e confirms that a larger COT on average leads to a smaller surface sensitivity.

The right column in Fig. 12 shows the respective plots for the LTA revealing a similar but weaker dependence of the sensitivity filter on LTA than COT. This is not surprising since there is presumably some cross-correlation between COT and LTA because clouds with a larger top altitude are potentially optically thicker. The histogram in Fig. 12a shows one dominating accumulation point for LTA $<1 \mathrm{~km}$ caused by cloud-free CALIOP measurements which are set to $\mathrm{LTA}=0$. Therefore, the dependence of the number of measurements classified as possibly obscured (Fig. 12d) shows the strongest gradient between 0 and $2 \mathrm{~km} \mathrm{LTA}$. The dependence on LTA vanishes between 2 and $8 \mathrm{~km}$ but increases again for high clouds (LTA $>8 \mathrm{~km}$ ). Finally, Fig. $12 \mathrm{f}$ shows the dependence of $A_{500}$ on LTA. The linear fit to all data shows a relatively slowly decreasing slope (black line). The slope becomes steeper, however, if only measurements below $2 \mathrm{~km}$ LTA are taken into account (red line). Hence, $A_{500}$ depends more strongly on the presence of low clouds which results from the concentration profile of $\mathrm{O}_{4}$, whose slope decreases with altitude.

Within the limitations of the CALIOP data set (relatively low maximum cloud optical depth, which can be measured) and of a comparison of different data sets, it can be concluded that the algorithm is capable of identifying the shielding effect of clouds over sea ice. GOME-2 pixels with a higher average COT and LTA are more likely classified as possibly obscured. A higher threshold $\mathrm{AMF}_{500}^{\mathrm{min}}$ increases the sensitivity of the filter towards filtering thinner and higher clouds. The LTA, however, was expected not to play such an important role because $A_{500}$ is almost constant for clouds higher than $500 \mathrm{~m}$.

The dependence on LTA illustrates the limits of the presented filter approach based on the utilisation of $\mathrm{O}_{4}$ as a tracer for near-surface air. $\mathrm{O}_{4}$ is also abundant above $500 \mathrm{~m}$ altitude implying the following limitations. Firstly, the shielding effect of very low and optically thick clouds may be underestimated because, in this case, $S_{\mathrm{O}_{4}}$ is almost not affected. Secondly, a pixel may also be filtered although the measurement is sensitive to the $\mathrm{BrO}$ present in that pixel. Therefore, filtered measurements are flagged as only possibly obscured. Example scenarios that appear as obscured but are in fact sensitive could be either a layer of $\mathrm{BrO}$ over a relatively dark surface elevated high enough to be detected anyway or near-surface $\mathrm{BrO}$ residing below high, optically thin clouds over a rather bright surface which may reduce $S_{\mathrm{O}_{4}}$ more strongly than the real $A_{500}$. The strength of the presented filter algorithm, however, is that measurements flagged as sensitive are very likely to be actually sensitive to near-surface $\mathrm{BrO}$ as the first limitation can be assumed to be less frequent in reality than the second.

\section{Comparison to ground-based measurements}

In this section, tropospheric BrO VCDs from GOME-2 are compared to both LP-DOAS and MAX-DOAS measurements of $\mathrm{BrO}$ obtained during two Arctic field campaigns, respectively.

During March and April 2008, Pöhler et al. (2010) measured $\mathrm{BrO}$ in the tropospheric boundary layer directly over the sea ice of the Amundsen Gulf from aboard the Amundsen research icebreaker. The data set from the Amundsen includes LP-DOAS and yet unpublished MAX-DOAS measurements. The LP-DOAS measured concentrations of $\mathrm{BrO}$ averaged between 1 and $19 \mathrm{~m}$ height above the sea ice. From MAX-DOAS measurements, BrO VCDs were calculated using the differential SCD between $10.6^{\circ}$ and $90^{\circ}$ divided by the differential AMF assuming clear-sky conditions and a surface albedo of 0.99 (Grenfell et al., 1994). 

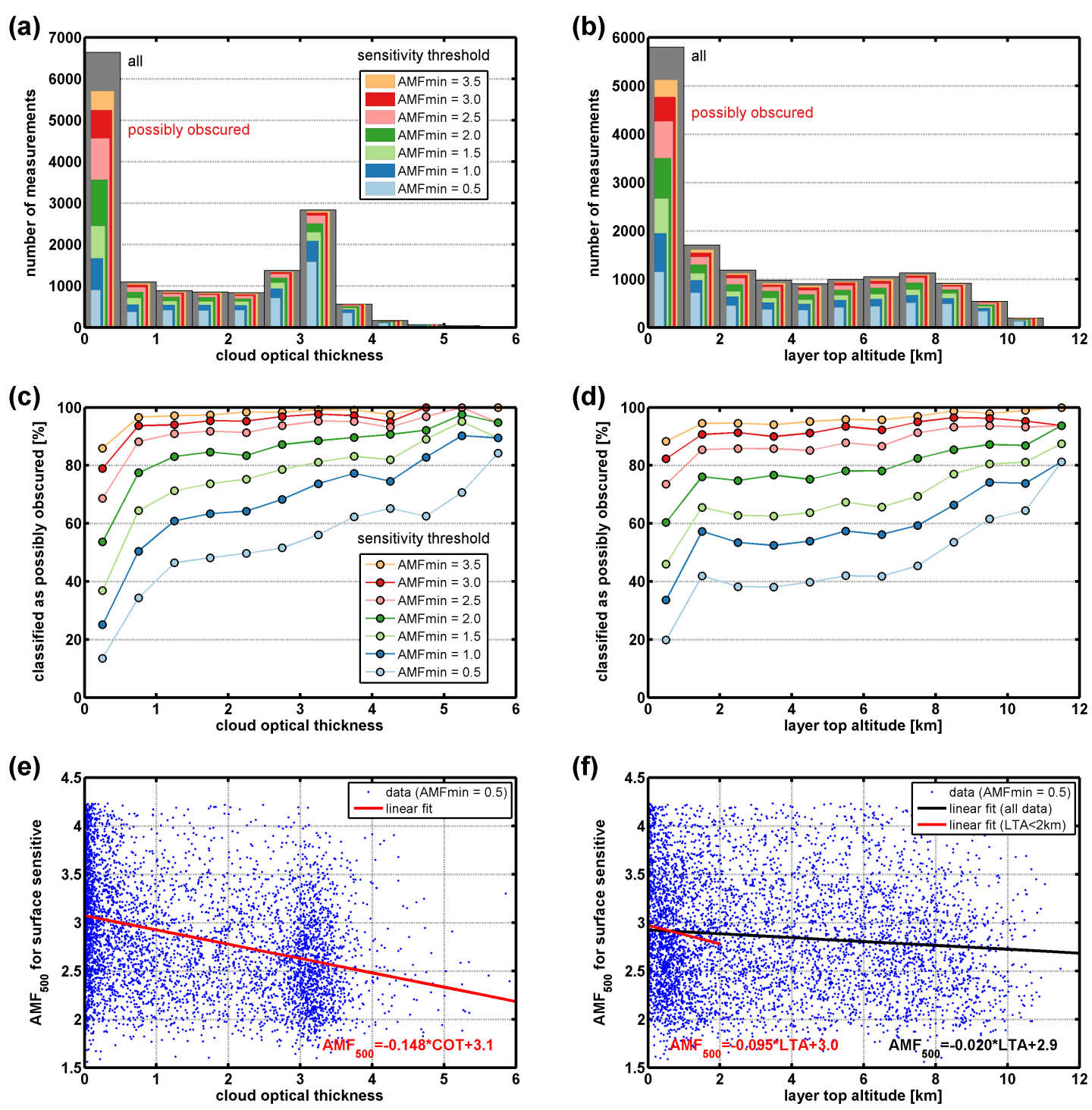

Fig. 12. Comparison between results of the surface sensitivity filter and collocated CALIPSO measurements over sea ice: CALIPSO cloud optical thickness (COT, left column) and CALIPSO layer top altitude (LTA, right column). (a) and (b) histograms of the unfiltered measurements compared to the histograms of measurements identified as possibly obscured at different sensitivity thresholds $\mathrm{AMF}_{500}^{\mathrm{min}}$; $(\mathbf{c})$ and $(\mathbf{d})$ ratio of filtered measurements depending on COT and LTA, respectively; (e) and (f) respective dependence of $A_{500}$ for $\mathrm{AMF}_{500}^{\mathrm{min}}=0.5$.

The other data set was collected between March and April 2009 during the Ocean-Atmosphere Sea-Ice Snowpack (OASIS, http://oasishome.net/) field initiative at Barrow, Alaska. The LP-DOAS measurements were presented in Liao et al. (2011). Vertical profiles of $\mathrm{BrO}$ and aerosols were retrieved from MAX-DOAS data using optimal estimation as described by Frieß et al. (2011). Tropospheric BrO VCDs were determined by integrating the retrieved MAX-DOAS profiles.

Both ground-based and satellite measurements offer their particular advantages and disadvantages to study the same phenomenon. Resolution and coverage differ between both approaches spatially and temporally. Ground-based instruments usually offer a higher spatial and temporal resolution, whereas satellite measurements observe the same property over a vast area at moderate spatial and temporal resolution. In conclusion, a high correlation may only be expected if both techniques sample the same volume of air, and spatial as well as temporal variabilities are small.

\subsection{Collocating satellite data and ground-based measurements}

In order to assure spatial and temporal coherence of groundbased and satellite measurements, coincident measurements have to be selected. Averages of collocated subsets are 
calculated for each overpass of the satellite. Note that a polar orbiting satellite may pass the same site several times a day during daylight depending on latitude, season, and type of swath. The swath of GOME-2 covers the studied sites up to three times a day at an SZA below $80^{\circ}$.

First of all, only those satellite measurements are selected that are sensitive to the ground (Sect. 2.3) and whose pixel footprint includes the location of the ground-based measurement. In a second step and for each satellite pixel, the time interval is calculated in which ground-based measurements are averaged. This calculation combines surface wind-speed and direction with the relative location of the measurement site within the GOME-2 pixel. If the measurement site is located close to the pixel edges, the averaging time-interval includes only those measurements corresponding to the air probed by both the satellite and ground-based instrumentation. This approach leads to a mean duration of approx. three hours which is limited to two hours prior to and after the time of the satellite overpass. Correlation coefficients as well as slope $a$ and $y$-intercept $b$ of a linear bivariate model (Cantrell, 2008) are calculated based on these overpass averages. Additionally, daily means including the overpass averages of each day are computed.

\subsection{Results from comparing satellite with ground-based measurements}

This section summarizes the results from both field campaigns, which are then discussed in Sect. 4.3.

For the Amundsen measurements, the time series of MAX-DOAS and LP-DOAS are shown together with the GOME-2 overpass data using a sensitivity threshold of $\mathrm{AMF}_{500}^{\mathrm{min}}=1$ in Figs. 13 and 14 and the corresponding correlation plots in Fig. 18a and 18b, respectively. The comparison to the MAX-DOAS measurements encompasses more than a month beginning on 9 March 2008. Both instruments, MAX-DOAS and GOME-2, captured several events of elevated tropospheric BrO VCDs including one major event around 14 March. Figure 15 shows a map of this particular event. The GOME-2 data furthermore reveal another particularly strong enhancement on 16 April 2008. The amplitudes of the collocated MAX-DOAS VCD time series are almost identical (slope close to unity), but there is a significant bias. The tropospheric column densities retrieved from GOME-2 measurements are systematically smaller by approx. $3 \times 10^{13}$ molec $^{-2}$ than measured by MAX-DOAS (Fig. 18a). The LP-DOAS measurements of the BrO mixing ratio, however, encompass only 16 days with collocated GOME-2 measurements interrupted by 5 days of cruise. The LP-DOAS measured up to $42 \mathrm{pmol} \mathrm{mol}^{-1}$ of $\mathrm{BrO}$ on 15 March when major enhancements were also observed by GOME-2 (see Supplement). The slope in Fig. 18b is approx. $500 \mathrm{~m}$, which represents an estimate for the BrO layer thickness.
The time series of both MAX-DOAS and LP-DOAS measurements at Barrow are shown in Figs. 16 and 17, respectively. More than a month of collocated measurements with GOME-2 from mid-March to mid-April 2009 are available. Compared to the measurements from aboard the Amundsen, the amplitudes of $\mathrm{BrO}$ enhancements (VCDs and mixing ratios) were generally smaller at Barrow. The correlations between GOME-2 and MAX-DOAS (Fig. 18c) as well as GOME-2 VCD and LP-DOAS mixing ratio (Fig. 18d) are weaker but statistically significant $\left(n=77, r^{2}=0.1, p=\right.$ 0.005). The slope in Fig. $18 \mathrm{c}$ reveals that the BrO VCDs retrieved from MAX-DOAS measurements are approx. twice as high as the collocated GOME-2 measurements. However, the offset between both data sets is significantly smaller than for the Amundsen measurements.

It is important to note that the temporal variability of LP-DOAS mixing ratios at Barrow occasionally deviates from GOME-2 tropospheric VCDs (Fig. 17). There are several days where the LP-DOAS measured above $10 \mathrm{pmol} \mathrm{mol}^{-1}$ while the GOME-2 VCDs are close to zero (16, 23, 29 March, and 11 April). On 14 March, however, both GOME-2 and MAX-DOAS show significantly elevated $\mathrm{BrO}$ columns while the LP-DOAS measured comparatively moderate $7 \mathrm{pmol} \mathrm{mol}^{-1}$. These differences are discussed in Sect. 4.3.

Finally, the dependence on the sensitivity threshold $\mathrm{AMF}_{500}^{\text {min }}$ is studied. The correlation coefficient $r^{2}$ is calculated for all four ground-based data sets and collocated GOME-2 measurements for different $\mathrm{AMF}_{500}^{\min }$ between 0.5 and 4 (Fig. 19). Furthermore, the respective number of remaining collocated measurements are shown. As already mentioned, the correlation between satellite and groundbased measurements is larger for the Amundsen than for the Barrow data. The increase in $r^{2}$ with $\mathrm{AMF}_{500}^{\mathrm{min}}$ is consistent for both MAX-DOAS comparisons indicating that the proposed sensitivity filter in fact identifies measurements with ambiguous sensitivity (Fig. 19a and c). For the LP-DOAS measurements, however, the trend for $r^{2}$ is less clear. For the Amundsen data, the correlation with LP-DOAS mixing ratios decreases significantly for $\mathrm{AMF}_{500}^{\mathrm{min}}>2$. At Barrow, $r^{2}$ increases only for rather high thresholds $\mathrm{AMF}_{500}^{\text {min }} \geq 3$ when more than half of the collocated measurements are filtered. For $\mathrm{AMF}_{500}^{\min }=3.2$ the correlation between LP-DOAS and GOME-2 is $r^{2}=0.19$ (see discussion bellow).

Gridded maps of daily satellite measurements corresponding to both time series can be found in the Supplement to this paper.

\subsection{Discussion of comparison with ground-based measurements}

The comparisons between ground-based and satellite measurements of BrO show a good agreement, demonstrating the capability of the presented method to retrieve realistic 


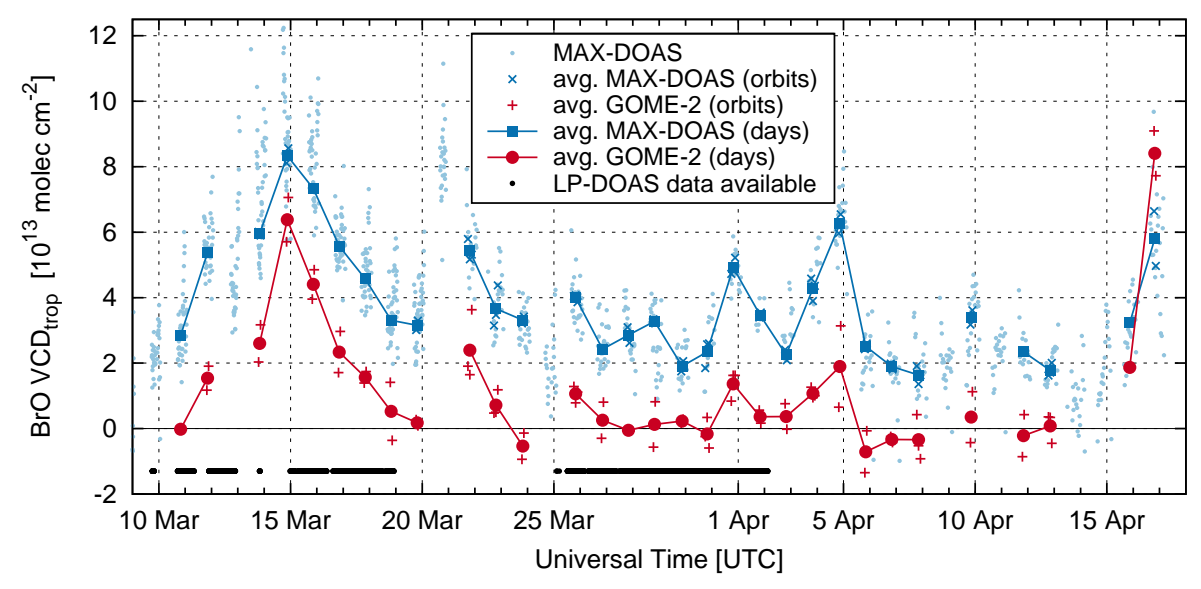

Fig. 13. Time series of MAX-DOAS BrO VCDs from aboard the Amundsen research icebreaker in 2008 compared to retrieved tropospheric BrO VCDs from GOME-2 $\left(\mathrm{AMF}_{500}^{\mathrm{min}}=1\right)$, same data as in Fig. 18a. The black dots denote periods of LP-DOAS measurements. Error bars are omitted for the sake of clarity.

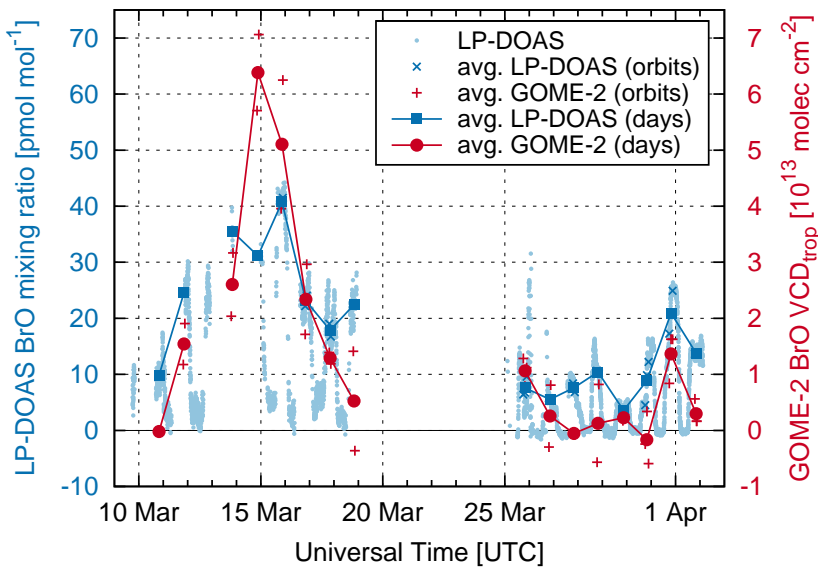

Fig. 14. Same as Fig. 13 but showing BrO mixing ratios measured by LP-DOAS. Both ordinates are scaled corresponding to a mixing height of $345 \mathrm{~m}$. Correlation in Fig. 18b.

tropospheric $\mathrm{BrO}$ column densities from GOME-2 measurements. The deviation from unity slopes for the correlation between GOME-2 VCDs and ground-based MAX-DOAS measurements for Amundsen and Barrow may be explained by a systematic difference of the sensitivity of both techniques with respect to the real distribution of BrO. The negative offset of GOME-2 VCDs compared to both MAX-DOAS time series possibly indicates that the presented algorithm underestimates the integrated tropospheric column. This systematic difference may be a result of the column separation algorithm (Sect. 2.2) for which it was assumed that the tropospheric column enhancement may reach zero. Hence, the negative offset indicates that there might be some residual $\mathrm{BrO}$ present almost everywhere in the Arctic during spring when also both presented LP-DOAS time series report significant $\mathrm{BrO}$ abundances every day (Pöhler et al., 2010; Liao

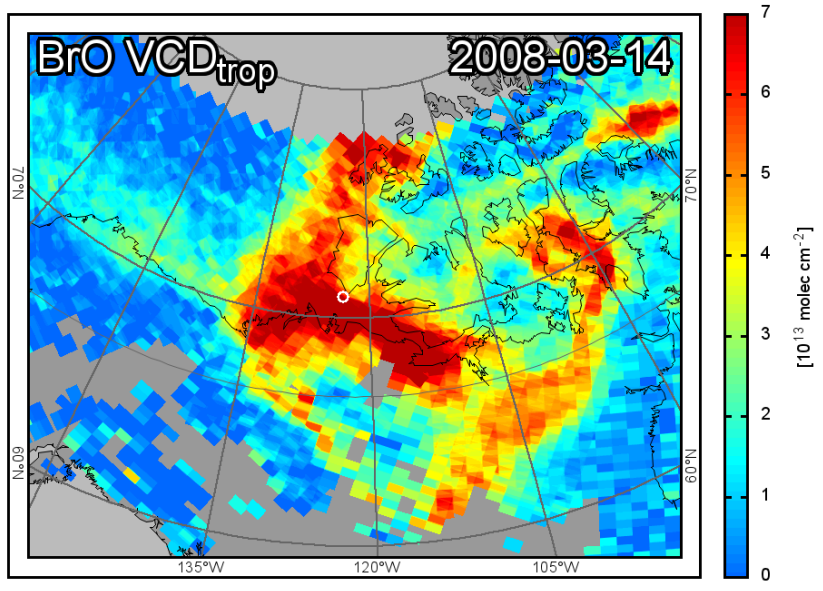

Fig. 15. Satellite map of tropospheric BrO VCDs measured by GOME-2 on 14 March 2008. The circle denotes the position of the Amundsen icebreaker. Further maps of the Amundsen campaign are shown in the Supplement.

et al., 2011). However, it is difficult to give a quantitative interpretation because both MAX-DOAS data sets were evaluated using different algorithms with different systematic errors. Furthermore, both MAX-DOAS and the GOME- 2 retrieval apply different AMFs which may furthermore lead to systematic differences. For example, the AMFs applied for the Amundsen measurements did not account for aerosol scattering which alters the sensitivity of the MAX-DOAS measurement with respect to GOME-2.

The comparison of LP-DOAS measurements aboard the Amundsen in spring 2008 and GOME-2 VCDs clearly indicates that surface concentrations of $\mathrm{BrO}$ may provide significant contributions to the $\mathrm{BrO}$ column of more than $6 \times 10^{13} \mathrm{molec} \mathrm{cm}^{-2}$ on $14 \mathrm{March}$. This corresponds to a surface $\mathrm{BrO}$ column extending to approx. $500 \mathrm{~m}$ altitude 


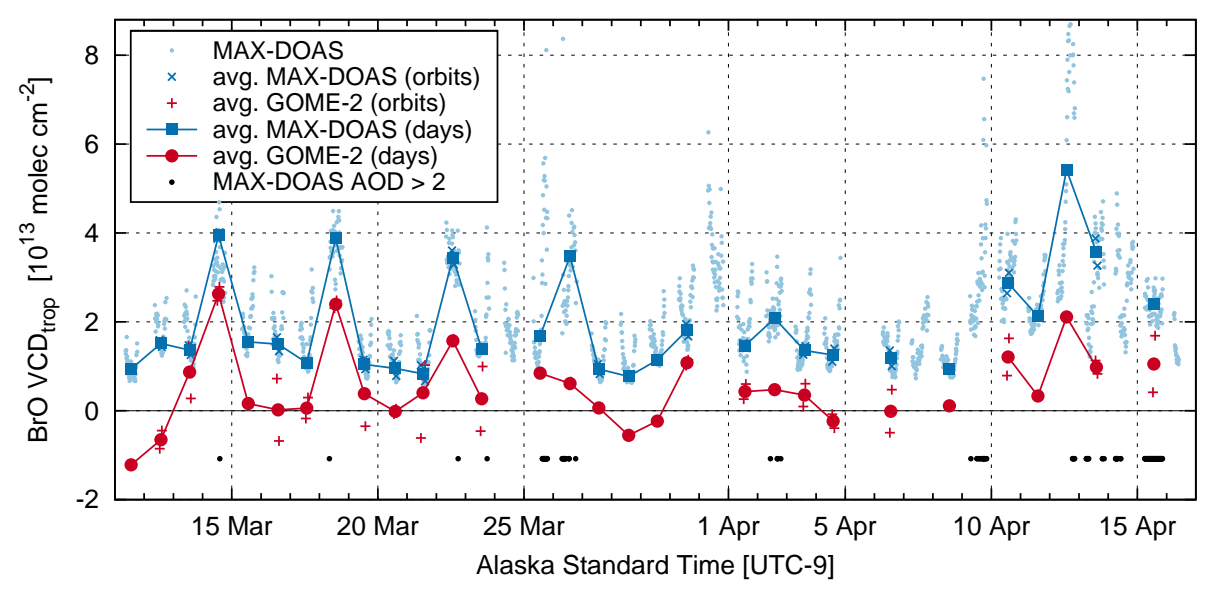

Fig. 16. Time series of retrieved BrO VCDs from ground-based MAX-DOAS measurements at Barrow, Alaska, 2009 compared to retrieved tropospheric BrO VCDs from GOME-2 $\left(\mathrm{AMF}_{500}^{\min }=1\right)$, same data as in Fig. 18c. Black dots denote MAX-DOAS measurements, where the surface aerosol optical density (AOD) exceeded 2. Error bars are omitted for the sake of clarity.

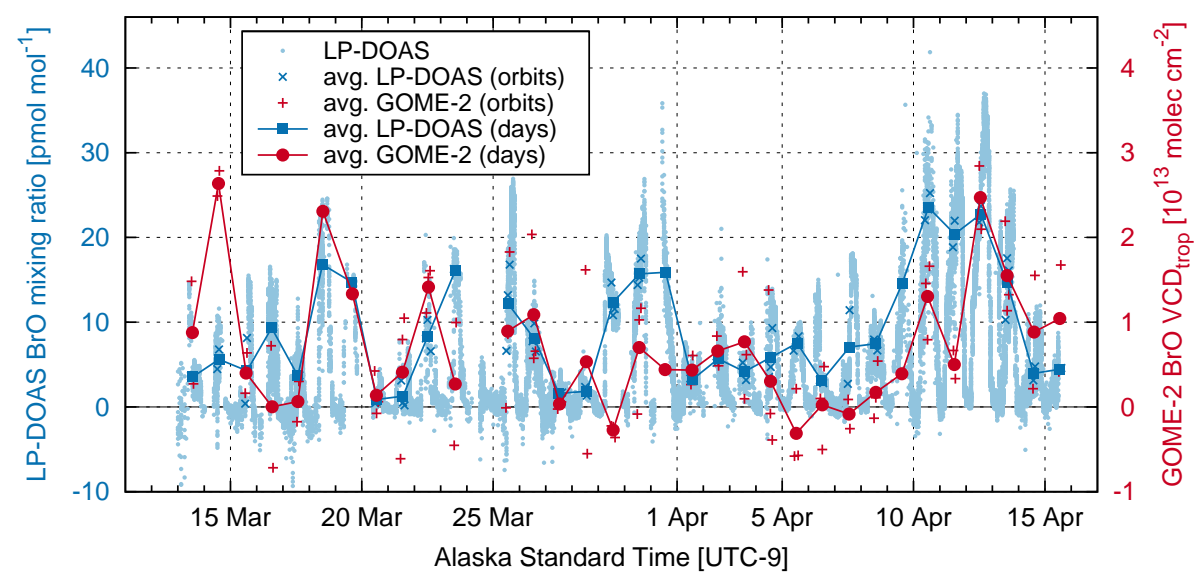

Fig. 17. Same as Fig. 16 but showing BrO mixing ratios measured by LP-DOAS. Both ordinates are scaled corresponding to a mixing height of $345 \mathrm{~m}$. Correlation in Fig. 18d.

(Fig. 18b) in agreement with the height of the simultaneously measured $\mathrm{O}_{3}$-depleted layer reported by Seabrook et al. (2011). The map of tropospheric $\mathrm{BrO}$ column densities (Fig. 15) shows a particularly large area affected by bromine activation. It is hence concluded that this particular "BrO cloud" is located at the surface but not in elevated layers, at least not at the location of the Amundsen vessel.

At Barrow, however, the correlation between LP-DOAS and GOME-2 measurements was much weaker than seen on the Amundsen vessel. There are several potential explanations for this behaviour.

i. The Barrow time series is much longer and the correlation comprises several strong events of elevated $\mathrm{BrO}$ levels. The height of the chemically perturbed boundary layer varied strongly between these events (Frieß et al., 2011; Helmig et al., 2012). Therefore, the assumption of a linear correlation may not be appropriate. ii. Located onshore, the local meteorology as well as surface processes related to bromine activation at Barrow may differ fundamentally from that over the sea ice. Furthermore, ground-based $\mathrm{O}_{3}$ measurements at Barrow revealed large horizontal heterogeneities (Liao et al., 2011; Helmig et al., 2012) which may bias the LP-DOAS measurements with respect to the satellite.

iii. The uncertainties of the sensitivity of the satellite measurement to the surface due to the nearby opening in the sea ice are large (cf. Sect. 3.3). In fact, increasing $\mathrm{AMF}_{500}^{\mathrm{min}}$ at Barrow resulted in an increased $r^{2}$ supporting this hypothesis. However, the comparison between MAX-DOAS and GOME-2 measurements at Barrow shows a good agreement despite the offset. Furthermore, the correlation of surface concentrations as measured by LP-DOAS and retrieved from MAX-DOAS measurements is significant (Frieß et al., 2011, Fig. 3). 

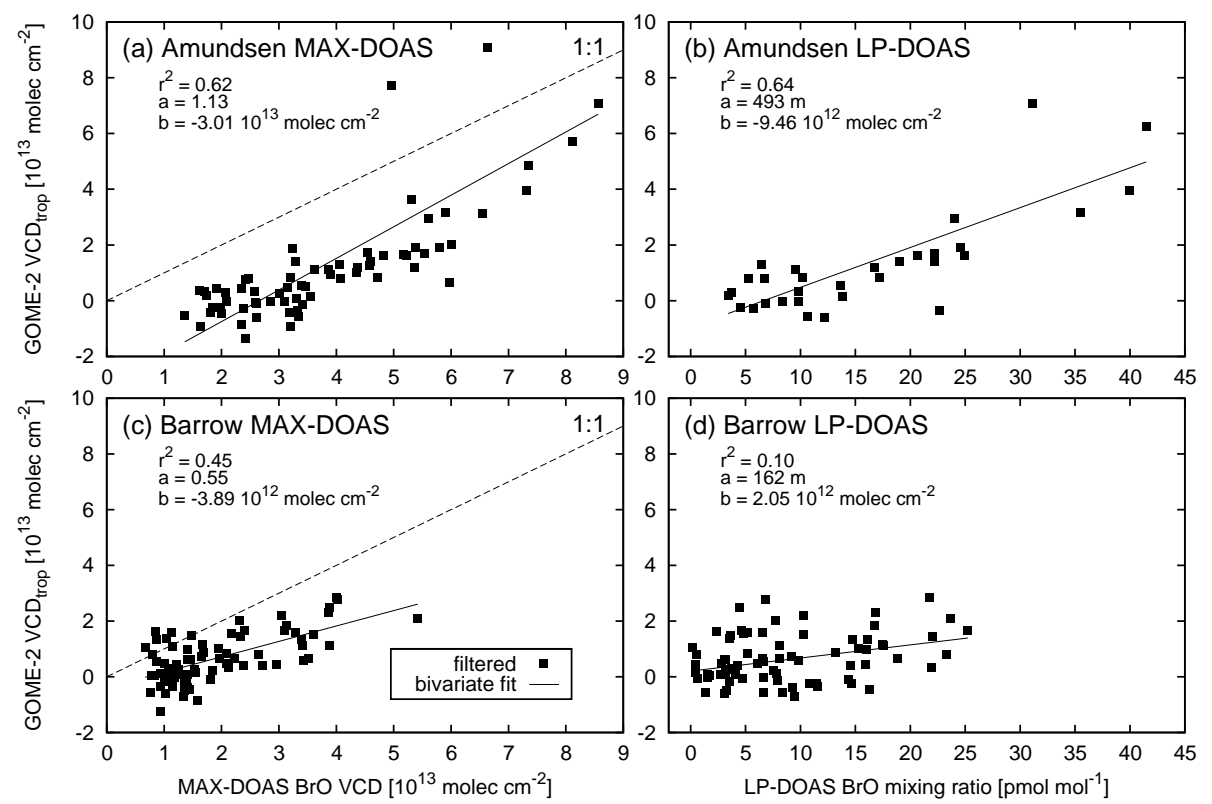

Fig. 18. Correlation and orthogonal fit of the different ground-based data sets with $\mathrm{VCD}_{\text {trop }}$ measured by GOME-2 $\left(A M F_{500}^{\mathrm{min}}=1\right)$. Note that the slopes in (b) and (d) are given in unit metre comparable to the height of the mixing-layer (assuming $\rho_{\text {air }}=2.9 \times 10^{19} \mathrm{molec}^{-3}$ ). Error bars are omitted for the sake of clarity.
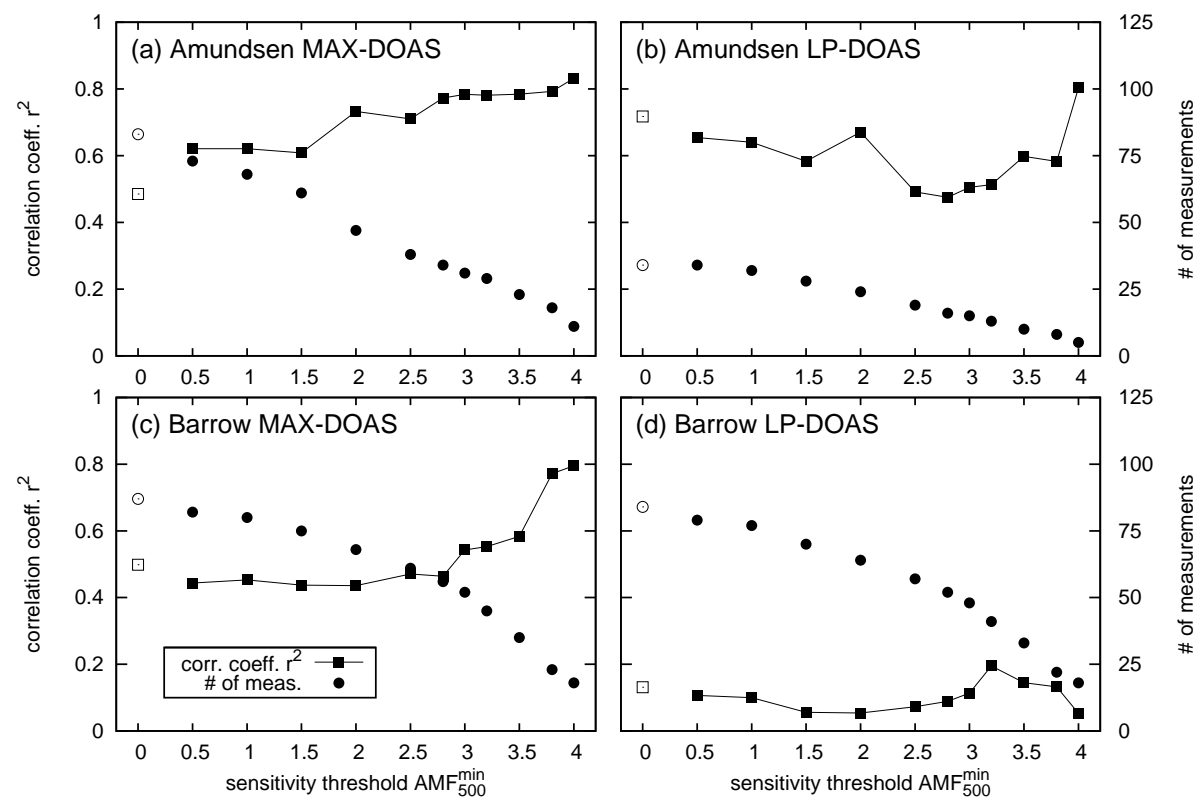

Fig. 19. Correlation coefficient $r^{2}$ and number of collocated ground-based and GOME-2 measurements depending on the applied sensitivity threshold $\mathrm{AMF}_{500}^{\mathrm{min}}$. Empty symbols denote correlations without sensitivity filter and geometric AMF applied.

This indicates that the VCDs measured by GOME-2 are realistic, and, hence, the variations of the $\mathrm{BrO}$ profile at Barrow were probably larger than during the Amundsen campaign where only one major event was captured by LP-DOAS. Occasionally enhanced near-surface $\mathrm{BrO}$ concentrations correspond to a shallower average mixing height of $\mathrm{BrO}$ as reproduced in Fig. 18d. In the following, two example days are selected in order to illustrate the vertical variability of the $\mathrm{BrO}$ profile.

As mentioned above, the LP-DOAS data in Fig. 17 show on several days considerably higher enhancements than GOME-2. This discrepancy can be explained by a very 

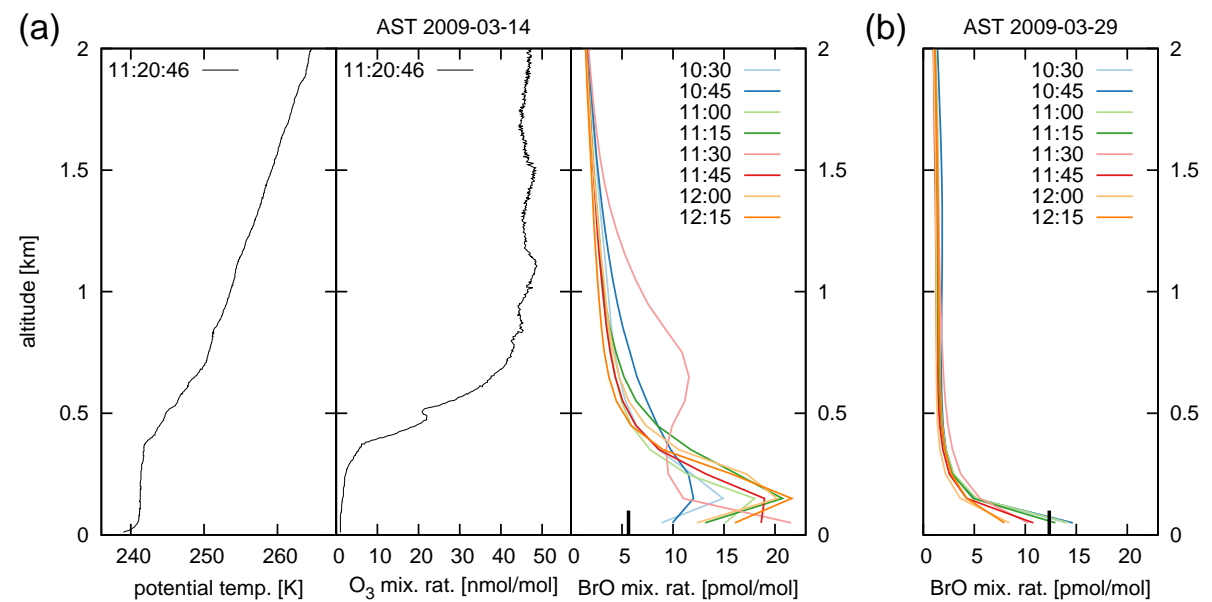

Fig. 20. (a) Profiles of potential temperature, $\mathrm{O}_{3}$, and $\mathrm{BrO}$ mixing ratio at Barrow on 14 March 2009. (b) BrO profile on $29 \mathrm{March} 2009$. The marks at the bottom of the BrO profiles denote the values measured by LP-DOAS. Potential temperature and $\mathrm{O}_{3}$ are measured by ozonesonde (courtesy of NOAA Earth System Research Laboratory). BrO profiles are retrieved from MAX-DOAS measurements (Frieß et al., 2011).

shallow layer of BrO (Fig. 20b). All shown MAX-DOAS profiles decrease to background values at altitude above $250 \mathrm{~m}$.

Another interesting event was captured at Barrow on 14 March 2009. GOME-2 observed a significantly elevated $\mathrm{BrO}$ column while the LP-DOAS shows only moderate levels of bromine activation. However, the comparison with the integrated tropospheric VCD from MAX-DOAS again shows good agreement, and the apparent discrepancy between LPDOAS and GOME-2 therefore indicates the presence of an elevated layer of enhanced $\mathrm{BrO}$ concentrations as suggested by e.g. Hönninger and Platt (2002), Wagner et al. (2007), and Frieß et al. (2011). In this context, the term elevated denotes a layer of enhanced $\mathrm{BrO}$ at a few hundred metres which are still within the boundary layer. On this day, $\mathrm{O}_{3}$ levels were below $1 \mathrm{nmol} \mathrm{mol}^{-1}$ suggesting a limited production of $\mathrm{BrO}$ at the surface (Helmig et al., 2012). As sampled by an ozonesonde launched at Barrow (Fig. 20a), the $\mathrm{O}_{3}$ mixing ratio increases with altitude allowing for a more efficient $\mathrm{BrO}$ production at these altitudes. Furthermore, the potential temperature gradient profile suggests a highly stratified boundary layer as well as a strong temperature inversion at the surface $(\sim 50 \mathrm{~m})$ hampering $\mathrm{O}_{3}$ mixing from aloft. This conclusion is supported by $\mathrm{BrO}$ profiles retrieved from MAX-DOAS measurements from the same day as depicted in Fig. 20a (Frieß et al., 2011). Despite one outlier retrieved from measurements around 11:30 AST, all retrieved profiles feature a positive $\mathrm{BrO}$ gradient close to the surface. However, most $\mathrm{BrO}$ is still located within the boundary layer.

From the data presented in this study, we conclude that events of enhanced $\mathrm{BrO}$ are well captured by satellite measurements, and that ground-based observation and tropospheric VCDs retrieved from GOME-2 data are significantly correlated. The near-surface concentrations measured by LPDOAS furthermore indicate that the satellite observations in turn are linked to surface processes as observed from aboard the Amundsen. At Barrow, however, deviations from this general dependence could be explained by local meteorological perturbations and variations of the surface $\mathrm{BrO}$ column height. Occasionally, satellite measurements may underestimate the influence by bromine activation when the surface $\mathrm{BrO}$ layer is extremely shallow and horizontal gradients of both the chemistry and the surface sensitivity are large. The general applicability of this observation, however, needs to be tested further because the presented study comprises only a relatively small number of ground-based observations over the sea ice.

\section{Conclusions}

We present a new algorithm to retrieve residual tropospheric columns of Arctic BrO solely based on data from a single satellite instrument. Two important properties of our algorithm are that it identifies measurements (a) with significantly enhanced tropospheric $\mathrm{BrO}$ amounts which cannot be explained by stratospheric processes and (b) are sensitive for near-surface layers. Unlike earlier attempts to solve this task, the presented approach does not depend on extensive chemistry models and climatological data. Only potential vorticity fields are supplied from external sources allowing to identify the polar vortex, where the retrieval algorithm is not applicable. This procedure is necessary to provide a consistent data set without artefacts caused by a disturbed stratospheric chemistry. Based on this work, possible surface processes involved in Arctic bromine activation can be studied.

Both the decomposition of the total column of $\mathrm{BrO}$ into stratospheric and residual tropospheric contribution as well as the surface sensitivity filter algorithm were validated through real measurements and simulated data. The resulting 
tropospheric $\mathrm{BrO}$ columns were compared to four independent $\mathrm{BrO}$ ground-based data sets and significant correlation was found. The comparison to ground-based data from two field campaigns taking place on- and off-shore confirmed that near-surface processes are the source of activated bromine compounds. While the correlation with MAX-DOAS VCDs was generally significant $\left(r^{2}>0.6\right)$, especially the comparison with LP-DOAS measurements at Barrow is less straightforward. However, the major deviations between LP-DOAS and GOME- 2 could be explained by the stratification of the surface layer and the profiles of both $\mathrm{BrO}$ and $\mathrm{O}_{3}$. Furthermore, it is occasionally possible that shallow surface layers and horizontal heterogeneities may obfuscate active bromine chemistry from satellite measurements.

Though only GOME-2 measurements were analysed, the presented algorithm is applicable to measurements performed by similar satellite instruments like GOME, SCIAMACHY, and the Ozone Monitoring Instrument (OMI) as well. Additionally, the algorithm to determine the sensitivity to trace-gas concentrations close to the surface is neither limited to retrievals of $\mathrm{BrO}$ nor to the Arctic. Any DOAS retrieval from satellites intended to study surface concentrations over bright surfaces may, in principle, apply the presented surface sensitivity filter, e.g. retrievals of iodine monoxide (IO) in the Antarctic troposphere.

\section{Appendix A}

\section{Computing of a partition $\Omega$}

A partition $\Omega_{\beta}$ of $\Omega=\left[\vartheta_{a}, \vartheta_{b}\right] \times\left[V_{\mathrm{N}_{a}}, V_{\mathrm{N}_{b}}\right] \times\left[\psi_{a}, \psi_{b}\right]$ is computed as follows. First of all, all previously selected reference measurements $T$ are divided in the $\psi$-direction into $N_{\psi}$ bins defined by the limits $\psi_{k}$ with $k=1, \ldots, N_{\psi}-1$ in order to separate the weak $\psi$-dependence from the following algorithm. Also, the viewing zenith angles are almost equally distributed over the entire instrument swath. In the $\vartheta$ and $V_{\mathrm{N}^{-}}$ direction, however, a partitioning algorithm accounting for non-uniform distributions is required. Partitions all containing a similar number of observations are desirable in order to achieve homogeneous statistics of the asymmetry filter applied on every partition separately.

The two-dimensional partitioning algorithm applied on each $\psi$-bin is based on a partition of $\Omega$ which can be indexed by two indices $i, j$ for the $\vartheta$ and $V_{\mathrm{N}}$-direction, respectively:

$\Omega_{\beta}=\Omega_{i, j}$.

The necessary steps are explained by means of a concrete example.

In order to sample the $\bar{z}$-surface in the two dimensions of the $\left(\vartheta, V_{\mathrm{N}}\right)$-plane, $T$ is subdivided into $N_{\vartheta}$ times $N_{V}$ partitions $\Omega_{i, j} \subset \Omega$ with $i=1, \ldots, N_{\vartheta}$ and $j=1, \ldots, N_{V}$, respectively. The partitioning is performed on the twodimensional domain $\Omega$ :

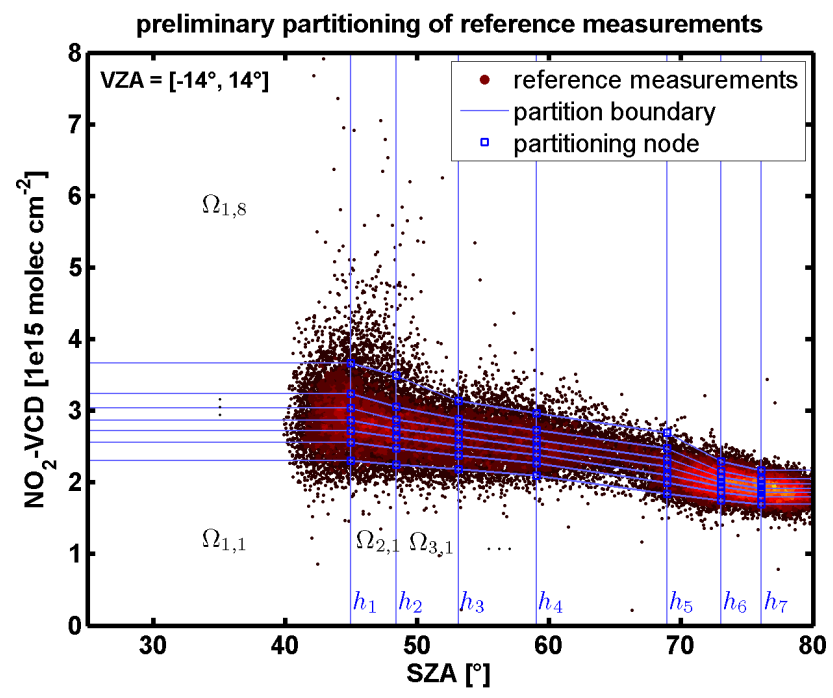

Fig. A1. Preliminary partitioning $\left(N_{\vartheta}, N_{V}=8\right)$ of GOME-2 reference measurements (color-coded density) for the near-nadir direction $\left(|\psi| \leq 14^{\circ}\right)$ whose final partitioning is shown in Fig. 3 .

$\Omega=\left[25^{\circ}, 80^{\circ}\right] \times\left[0,8 \times 10^{15}\right.$ molec cm $\left.^{-2}\right]$,

which encompasses the SZA interval between $25^{\circ}$ and $80^{\circ}$ and the $\mathrm{NO}_{2} \mathrm{VCD}$ interval between 0 and $8 \times$ $10^{15} \mathrm{molec}^{-2}$, respectively. The partitioning is first initialized and then iteratively optimized until each partition contains an almost equally large subset of $T$.

The partitioning of $\Omega$ is initialized in two steps. Figure A1 shows an example of this procedure performed on $\Omega$ for 25 March 2009. (1) $T$ is divided into $N_{\vartheta}$ preliminary partitions along the $\vartheta$-axis each containing an equal number of observations except the last two columns $\left(i=N_{\vartheta}-1, N_{\vartheta}\right)$, whose sizes are weighted by two in order to allow for a higher density of bins at this edge of the domain. The borders between the partitions are denoted $h_{i}\left(i=1, \ldots, N_{\vartheta}-1\right)$ in Fig. A1. (2) Subsequently, the preliminary partitioning nodes defining the boundaries of each partition in $V_{\mathrm{N}}$-direction are calculated. For each $i=1, \ldots, N_{\vartheta}-1$, we construct a set union $T_{i}$ :

$T_{i}=\bigcup_{j=1}^{N_{V}} T_{i, j} \bigcup_{j=1}^{N_{V}} T_{i+1, j}$,

which contains all observations in the column left and right of the respective $h_{i}$. Each $T_{i}$ is then divided into $N_{V}$ partitions in $V_{\mathrm{N}}$-direction defining the $\left(\vartheta, V_{\mathrm{N}}\right)$-coordinates of the preliminary partitioning nodes. This time, however, the first and last partition (top and bottom row) contain only half as many observations compared to the six partitions in between. The modification to the basic scheme of partitions containing an equal number of measurements prevents the outer partitions from becoming too large at the cost of retrieval noise. 
Finally, this procedure leads to a total of $N_{\theta} \times N_{V}$ initial partitioning nodes defining the boundaries of the partitions as depicted in Fig. A1.

After computing the initial coordinates of the partitioning nodes, the coordinates of the nodes are iteratively fine-tuned until all partitions contain an almost equal number of measurements. The fine-tuning is first performed for the node in the bottom left of Fig. A1 and then consecutively followed by the nodes to the right and then line-by-line upward. The fine-tuning is implemented as follows: it is tested how the variance of the number of measurements in the adjacent partitions behaves when the position of the actual boundary slightly changes. The node is consecutively displaced horizontally by $\pm \Delta \vartheta$ and vertically by $\pm \Delta V_{\mathrm{N}}$. If the variance at one of the four positions is smaller than at the old position, the new position with the minimum variance is chosen as the new position and the procedure is repeated in the neighbourhood of the new position. The fine-tuning of each node is repeated up to five times before moving on to the next node. $\Delta \vartheta$ and $\Delta V_{\mathrm{N}}$ depend on the minimum distance to neighbouring nodes in the respective direction and decrease in each iteration.

In order to finalize the partitioning algorithm, the number of measurements in all partitions is computed after all nodes have been fine-tuned separately. The fine-tuning algorithm is terminated when the number variation is less than $20 \%$ (the first and last row of partitions $T_{i, j}$ for $i=V_{\vartheta}$ and $j=1, V_{\mathrm{N}}$ are treated differently as described above). Otherwise the fine-tuning is repeated for all nodes until the $20 \%$ criterion is reached. Usually, the algorithm converges after 5 repetitions or less. Figure 3 illustrates the final partitioning of $\Omega$. Numerical inspection presented in Sect. 3.1 revealed that values of $N_{\vartheta}=5$ and $N_{\vartheta}=N_{V}=8$ lead to sufficiently accurate results. The limits of the bins in $\psi$-direction are fixed to $\pm 14^{\circ}$ and $\pm 34^{\circ}$, respectively.

\section{Supplementary material related to this article is available online at: http://www.atmos-meas-tech.net/5/ 2779/2012/amt-5-2779-2012-supplement.pdf.}

Acknowledgements. Inspiring discussions with the following individuals during the preparation of this work are heartily acknowledged: N. Theys (IASB/BIRA), J. Buxmann (IUP Heidelberg), G. Ziegler (Uni Jena), L. Kaleschke (Uni Hamburg), and J. Ström (Uni Troms $\varnothing$ ). For their technical support R. Sörensen and K. Mies at MPIC are acknowledged. AMSR-E sea-ice concentration maps have been provided by the ICDC, KlimaCampus Hamburg. Patrick Jöckel (DLR) is acknowledged for providing data from EMAC model simulations. M. Van Roozendael and C. Fayt from IASB/BIRA are acknowledged for providing the WinDOAS software. GOME-2 and AVHRR level-1 data have been provided by EUMETSAT. ECMWF operational data have been obtained from the ECMWF Data Server. CALIPSO data have been obtained from the NASA Langley Research Center Atmospheric Science Data Center. The ozone profile was provided by NOAA Earth System Research Laboratory (ESRL, http://www.esrl.noaa.gov/gmd/obop/brw). This work has been financially supported by the German Research Association (FR2497/2-1 and PL193/10-1) and the International Max Planck Research School for Atmospheric Chemistry and Physics, Mainz (Germany).

The service charges for this open access publication have been covered by the Max Planck Society.

Edited by: P. Stammes

\section{References}

Acarreta, J. R., De Haan, J. F., and Stammes, P.: Cloud pressure retrieval using the $\mathrm{O}_{2}-\mathrm{O}_{2}$ absorption band at $477 \mathrm{~nm}$, J. Geophys. Res., 109, D05204, doi:10.1029/2003JD003915, 2004.

Afe, O., Richter, A., Sierk, B., Wittrock, F., and Burrows, J.: BrO emission from volcanoes: a survey using GOME and SCIAMACHY measurements, Geophys. Res. Lett., 31, L24113, doi:10.1029/2004GL020994, 2004.

Aliwell, S. R., Van Roozendael, M., Johnston, P. V., Richter, A., Wagner, T., Arlander, D. W., Burrows, J. P., Fish, D. J., Jones, R. L., Tørnkvist, K. K., Lambert, J.-C., Pfeilsticker, K., and Pundt, I.: Analysis for $\mathrm{BrO}$ in zenith-sky spectra: an intercomparison exercise for analysis improvement, J. Geophys. Res., 107, 4199, doi:10.1029/2001JD000329, 2002.

Atkinson, R., Baulch, D. L., Cox, R. A., Crowley, J. N., Hampson, R. F., Hynes, R. G., Jenkin, M. E., Rossi, M. J., and Troe, J.: Evaluated kinetic and photochemical data for atmospheric chemistry: Volume III - gas phase reactions of inorganic halogens, Atmos. Chem. Phys., 7, 981-1191, doi:10.5194/acp-7-981-2007, 2007.

Barrie, L. A., Bottenheim, J. W., Schnell, R. C., Crutzen, P. J., and Rasmussen, R.: Ozone destruction and photochemical reactions at polar sunrise in the lower Arctic atmosphere, Nature, 334 138-141, 1988.

Begoin, M., Richter, A., Weber, M., Kaleschke, L., Tian-Kunze, X., Stohl, A., Theys, N., and Burrows, J. P.: Satellite observations of long range transport of a large $\mathrm{BrO}$ plume in the Arctic, Atmos. Chem. Phys., 10, 6515-6526, doi:10.5194/acp-10-65152010, 2010.

Bogumil, K., Orphal, J., Homann, T., Voigt, S., Spietz, P., and Fleischmann, O.: Measurements of molecular absorption spectra with the SCIAMACHY pre-flight model: instrument characterization and reference data for atmospheric remote-sensing in the 230-2380 nm region, J. Photoch. Photobio. A, 157, 167-184, doi:10.1016/S1010-6030(03)00062-5, 2003.

Burrows, J., Dehn, A., Deters, B., Himmelmann, S., Richter, A., and Voigt, S.: Atmospheric remote-sensing reference data from GOME: Part 1. Temperature-dependent absorption crosssections of $\mathrm{NO}_{2}$ in the 231-794 nm range, J. Quant. Spectrosc. Ra., 60, 1025-1031, doi:10.1016/S0022-4073(97)001970, 1998.

Callies, J., Corpaccioli, E., Eisinger, M., Hahne, A., and Lefebvre, A.: GOME-2 - MetOp's second-generation sensor for operational ozone monitoring, ESA Bull., 102, 28-36, 2000. 
Cantrell, C. A.: Technical Note: Review of methods for linear leastsquares fitting of data and application to atmospheric chemistry problems, Atmos. Chem. Phys., 8, 5477-5487, doi:10.5194/acp8-5477-2008, 2008.

Chance, K.: Analysis of BrO measurements from the global ozone monitoring experiment, Geophys. Res. Lett., 25, 3335-3338, doi:10.1029/98GL52359, 1998.

Choi, S., Wang, Y., Salawitch, R. J., Canty, T., Joiner, J., Zeng, T., Kurosu, T. P., Chance, K., Richter, A., Huey, L. G., Liao, J., Neuman, J. A., Nowak, J. B., Dibb, J. E., Weinheimer, A. J., Diskin, G., Ryerson, T. B., da Silva, A., Curry, J., Kinnison, D., Tilmes, S., and Levelt, P. F.: Analysis of satellite-derived Arctic tropospheric $\mathrm{BrO}$ columns in conjunction with aircraft measurements during ARCTAS and ARCPAC, Atmos. Chem. Phys., 12, 1255-1285, doi:10.5194/acp-12-1255-2012, 2012.

Clémer, K., Van Roozendael, M., Fayt, C., Hendrick, F., Hermans, C., Pinardi, G., Spurr, R., Wang, P., and De Mazière, M.: Multiple wavelength retrieval of tropospheric aerosol optical properties from MAXDOAS measurements in Beijing, Atmos. Meas. Tech., 3, 863-878, doi:10.5194/amt-3-863-2010, 2010.

De Smedt, I., Van Roozendael, M., and Jacobs, T.: Optimization of DOAS settings for BrO fitting from SCIAMACHY nadir spectra - comparison with GOME BrO retrievals, Tech. rep., Belg. Inst. for Space Aeron., Brussels, Belgium, available at: http://bro. aeronomie.be/BIRA_SCIABrO.pdf (last access: 2 May 2012), 2004.

Deutschmann, T., Beirle, S., Frieß, U., Grzegorski, M., Kern, C., Kritten, L., Platt, U., Prados-Román, C., Pukite, J., Wagner, T., Werner, B., and Pfeilsticker, K.: The Monte Carlo atmospheric radiative transfer model McArtim: introduction and validation of Jacobians and 3-D features, J. Quant. Spectrosc. Ra., 112, 11191137, doi:10.1016/j.jqsrt.2010.12.009, 2011.

Dikty, S., Richter, A., Weber, M., Noël, S., Bovensmann, H., Wittrock, F., and Burrows, J. P.: GOME-2 on MetOp-A Support for Analysis of GOME-2 In-Orbit Degradation and Impacts on Level 2 Data Products - Final Report, Tech. rep., Inst. of Environ. Phys., Bremen, Germany, available at: www.eumetsat.int, document ITT 09/10000262 (last access: 25 September 2012), 2011.

Dorf, M., Butler, J. H., Butz, A., Camy-Peyret, C., Chipperfield, M. P., Kritten, L., Montzka, S. A., Simmes, B., Weidner, F., and Pfeilsticker, K.: Long-term observations of stratospheric bromine reveal slow down in growth, Geophys. Res. Lett., 33, L24808, doi:10.1029/2006GL027714, 2006.

Frieß, U., Sihler, H., Sander, R., Pöhler, D., Yilmaz, S., and Platt, U.: The vertical distribution of $\mathrm{BrO}$ and aerosols in the Arctic: measurements by active and passive differential optical absorption sprectroscopy, J. Geophys. Res., 116, D00R04, doi:10.1029/2011JD015938, 2011.

Grainger, J. F. and Ring, J.: Anomalous Fraunhofer line profiles, Nature, 193, p. 762, doi:10.1038/193762a0, 1962.

Greenblatt, G., Orlando, J., Burkholder, J., and Ravishankara, A.: Absorption measurements of oxygen between 330 and $1140 \mathrm{~nm}$, J. Geophys. Res., 95, 18577-18582, doi:10.1029/JD095iD11p18577, 1990.

Grenfell, T. C., Warren, S. G., and Mullen, P. C.: Reflection of solar radiation by the Antarctic snow surface at ultraviolet, visible, and near-infrared wavelengths, J. Geophys. Res., 99, 18669-18684, doi:10.1029/94JD01484, 1994.
Gür, B., Spietz, P., Orphal, J., and Burrows, J.: Absorption Spectra Measurements with the GOME-2 FMs using the IUP/IFE-UBs Calibration Apparatus for Trace Gas Absorption Spectroscopy CATGAS, Final Report, Tech. rep., IUP University of Bremen, Germany, 2005.

Hausmann, M. and Platt, U.: Spectroscopic measurement of bromine oxide and ozone in the high Arctic during the polar sunrise experiment 1992, J. Geophys. Res., 99, 25399-25413, doi:10.1029/94JD01314, 1994.

Helmig, D., Boylan, P., Johnson, B., Oltmans, S., Fairall, C., Staebler, R., Weinheimer, A., Orlando, J., Knapp, D. J., Montzka, D. D., Flocke, F., Frieß, U., Sihler, H., and Shepson, P. B.: Ozone dynamics and snow-atmosphere exchanges during ozone depletion events at Barrow, AK, J. Geophys. Res., 117, D20303, doi:10.1029/2012JD017531, 2012.

Heue, K.-P., Brenninkmeijer, C. A. M., Baker, A. K., RautheSchöch, A., Walter, D., Wagner, T., Hörmann, C., Sihler, H., Dix, B., Frieß, U., Platt, U., Martinsson, B. G., van Velthoven, P. F. J., Zahn, A., and Ebinghaus, R.: $\mathrm{SO}_{2}$ and $\mathrm{BrO}$ observation in the plume of the Eyjafjallajökull volcano 2010: CARIBIC and GOME-2 retrievals, Atmos. Chem. Phys., 11, 2973-2989, doi:10.5194/acp-11-2973-2011, 2011.

Hollwedel, J., Wenig, M., Beirle, S., Kraus, S., Kühl, S., WilmsGrabe, W., Platt, U., and Wagner, T.: Year-to-year variations of spring time polar tropospheric $\mathrm{BrO}$ as seen by GOME, Adv. Space Res., 34, 804-808, doi:10.1016/j.asr.2003.08.060, 2004.

Hönninger, G. and Platt, U.: Observations of $\mathrm{BrO}$ and its verticaldistribution during surface ozone depletion at Alert, Atmos. Environ., 36, 2482-2489, 2002.

Hönninger, G., Leser, H., Sebastián, O., and Platt, U.: Ground-based measurements of halogen oxides at the Hudson Bay by active longpath DOAS and passive MAX-DOAS, Geophys. Res. Lett., 31, L04111, doi:10.1029/2003GL018982, 2004.

Jöckel, P., Kerkweg, A., Pozzer, A., Sander, R., Tost, H., Riede, H., Baumgaertner, A., Gromov, S., and Kern, B.: Development cycle 2 of the Modular Earth Submodel System (MESSy2), Geosci. Model Dev., 3, 717-752, doi:10.5194/gmd-3-717-2010, 2010.

Kaleschke, L., Lupkes, C., Vihma, T., Haarpaintner, J., and Bochert, A.: SSM/I sea ice remote sensing for mesoscale oceanatmosphere interaction analysis, Can. J. Remote Sens., 27, 526537, 2001.

Kaleschke, L., Richter, A., Burrows, J., Afe, O., Heygster, G., Notholt, J., Rankin, A. M., Roscoe, H. K., Hollwedel, J., Wagner, T., and Jacobi, H.-W.: Frost flowers on sea ice as a source of sea salt and their influence on tropospheric halogen chemistry, Geophys. Res. Lett., 31, L16114, doi:10.1029/2004GL020655, 2004.

King, M. D.: Determination of the scaled optical thickness of clouds from reflected solar radiation measurements, J. Atmos. Sci., 44, 1734-1751, doi:10.1175/15200469(1987)044<1734:DOTSOT>2.0.CO;2, 1987.

Koelemeijer, R. B. A., Stammes, P., Hovenier, J. W., and de Haan, J. F.: A fast method for retrieval of cloud parameters using oxygen A band measurements from Global Ozone Monitoring Experiment, J. Geophys. Res., 106, 3475-3490, doi:10.1029/2000JD900657, 2001.

Kraus, S.: DOASIS: DOAS Intelligent Sytem, Software, copyright 2004 Stefan Kraus, Institute of Environmental Physics, University of Heidleberg, in cooperation with Hoffmann Messtechnik 
GmbH, Heidelberg, 2004.

Liao, J., Sihler, H., Huey, L., Neuman, J., Tanner, D., Friess, U., Platt, U., Flocke, F. M., Orlando, J. J., Shepson, P. B., Beine, H. J., Weinheimer, A. J., Sjostedt, S. J., Nowak, J. B., Knapp, D. J., Staebler, R. M., Zheng, W., Sander, R., Hall, S. R., and Ullmann, K.: A comparison of Arctic BrO measurements by chemical ionization mass spectrometry and long path-differential optical absorption spectroscopy, J. Geophys. Res., 116, D00R02, doi:10.1029/2010JD014788, 2011.

Martin, R. V., Chance, K., Jacob, D., Kurosu, T. P., Spurr, R. J. D., Bucsela, E., Gleason, J. F., Palmer, P. I., Bey, I., Fiore, A. M., Li, Q., Yantosca, R. M., and Koelemeijer, R. B. A.: An improved retrieval of tropospheric nitrogen dioxide from GOME, J. Geophys. Res., 107, 4437, doi:10.1029/2001JD001027, 2002.

Munro, R., Eisinger, M., Anderson, C., Callies, J., Corpaccioli, E., Lang, R., Lefebvre, A., Livschitz, Y., and Albiñana, A. P.: GOME-2 on MetOp, in: Proc. of The 2006 EUMETSAT Meteorological Satellite Conference, Helsinki, Finland, 12-16 June 2006, ISBN 92-9110-076-5, EUMETSAT, 48, 2006.

NASA: CloudSat-CALIPSO Launch, Press kit, National Aeronautics and Space Administration, http://www.jpl.nasa.gov/news/ press_kits/cloudsat-calipso-launch.pdf (last access: 2 May 2011), 2006.

O’Byrne, G., Martin, R. V., van Donkelaar, A., Joiner, J., and Celarier, E. A.: Surface reflectivity from the ozone monitoring instrument using the moderate resolution imaging spectroradiometer to eliminate clouds: effects of snow on ultraviolet and visible trace gas retrievals, J. Geophys. Res., 115, D17305, doi:10.1029/2009JD013079, 2010.

Platt, U. and Stutz, J.: Differential Optical Absorption Spectroscopy (DOAS) - Principles and Applications, Springer-Verlag, Berlin, Heidelberg, 2008.

Pöhler, D., Vogel, L., Frieß, U., and Platt, U.: Observation of halogen species in the Amundsen Gulf, Arctic, by active long-path differential optical absorption spectroscopy, P. Natl. Acad. Sci. USA, 107, 6582-6587, doi:10.1073/pnas.0912231107, 2010.

Prados-Roman, C., Butz, A., Deutschmann, T., Dorf, M., Kritten, L., Minikin, A., Platt, U., Schlager, H., Sihler, H., Theys, N., Van Roozendael, M., Wagner, T., and Pfeilsticker, K.: Airborne DOAS limb measurements of tropospheric trace gas profiles: case studies on the profile retrieval of $\mathrm{O}_{4}$ and $\mathrm{BrO}$, Atmos. Meas. Tech., 4, 1241-1260, doi:10.5194/amt-4-1241-2011, 2011.

Press, W. H., Teukolsky, S. A., Vetterling, W. T., and Flannery, B. P.: Numerical Recepies in $\mathrm{C}++$, 3rd Edn., Cambridge University Press, Cambridge, New York, 2007.

Quarteroni, A., Sacco, R., and Saleri., F.: Numerische Mathematik 2, Springer Verlag, Berlin Heidelberg, 2002.

Richter, A., Wittrock, F., Eisinger, M., and Burrows, J.: GOME observations of tropospheric $\mathrm{BrO}$ in northern hemispheric spring and summer 1997, Geophys. Res. Lett., 25, 2683-2686, doi:10.1029/98GL52016, 1998.

Richter, A., Wittrock, F., Ladstätter-Weißenmayer, A., and Burrows, J. P.: GOME measurements of stratospheric and tropospheric BrO, Adv. Space Res., 29, 1667-1672, doi:10.1016/S0273-1177(02)00123-0, 2002.

Rothman, L., Gamache, R., Tipping, R., Rinsland, C., Smith, M., and Benner, D.: The HITRAN molecular database - editions of 1991 and 1992, J. Quant. Spectrosc. Ra., 48, 469-507, 1992.
Salawitch, R. J., Canty, T., Kurosu, T., Chance, K., Liang, Q., da Silva, A., Pawson, S., Nielsen, J. E., Rodriguez, J. M., Bhartia, P. K., Liu, X., Huey, L. G., Liao, J., Stickel, R. E., Tanner, D. J., Dibb, J. E., Simpson, W. R., Donohoue, D., Weinheimer, A., Flocke, F., Knapp, D., Montzka, D., Neuman, J. A., Nowak, J. B., Ryerson, T. B., Oltmans, S., Blake, D. R., Atlas, E. L., Kinnison, D. E., Tilmes, S., Pan, L. L., Hendrick, F., Van Roozendael, M., Kreher, K., Johnston, P. V., Gao, R. S., Johnson, B., Bui, T. P., Chen, G., Pierce, R. B., Crawford, J. H., and Jacob, D. J.: A new interpretation of total column $\mathrm{BrO}$ during arctic spring, Geophys. Res. Lett., 37, L21805, doi:10.1029/2010GL043798, 2010.

Seabrook, J. A., Whiteway, J., Staebler, R. M., Bottenheim, J. W., Komguem, L., Gray, L. H., Barber, D., and Asplin, M.: LIDAR measurements of Arctic boundary layer ozone depletion events over the frozen Arctic Ocean, J. Geophys. Res., 116, D00S02, doi:10.1029/2011JD016335, 2011.

Simpson, W. R., von Glasow, R., Riedel, K., Anderson, P., Ariya, P., Bottenheim, J., Burrows, J., Carpenter, L. J., Frieß, U., Goodsite, M. E., Heard, D., Hutterli, M., Jacobi, H.-W., Kaleschke, L., Neff, B., Plane, J., Platt, U., Richter, A., Roscoe, H., Sander, R., Shepson, P., Sodeau, J., Steffen, A., Wagner, T., and Wolff, E.: Halogens and their role in polar boundary-layer ozone depletion, Atmos. Chem. Phys., 7, 4375-4418, doi:10.5194/acp-7-43752007, 2007.

Sinnhuber, B.-M., Arlander, D. W., Bovensmann, H., Burrows, J. P., Chipperfield, M. P., Enell, C.-F., Frieß, U., Hendrick, F., Johnston, P. V., Jones, R. L., Kreher, K., Mohamed-Tahrin, N., Müller, R., Pfeilsticker, K., Platt, U., Pommereau, J.-P., Pundt, I., Richter, A., South, A. M., Tørnkvist, K. K., Van Roozendael, M., Wagner, T., and Wittrock, F.: Comparison of measurements and model calculations of stratospheric bromine monoxide, J. Geophys. Res.-Biogeo., 107, 4398, doi:10.1029/2001JD000940, 2002.

Spreen, G., Kaleschke, L., and Heygster, G.: Sea ice remote sensing using AMSR-E 89-GHz channels, J. Geophys. Res.-Biogeo., 113, C02S03, doi:10.1029/2005JC003384, 2008.

Stutz, J. and Platt, U.: Numerical analysis and estimation of the statistical error of differential optical absorption spectroscopy measurements with least-squares methods, Appl. Optics, 35, 60416053, doi:10.1364/AO.35.006041, 1996.

Theys, N., Van Roozendael, M., Errera, Q., Hendrick, F., Daerden, F., Chabrillat, S., Dorf, M., Pfeilsticker, K., Rozanov, A., Lotz, W., Burrows, J. P., Lambert, J.-C., Goutail, F., Roscoe, H. K., and De Mazière, M.: A global stratospheric bromine monoxide climatology based on the BASCOE chemical transport model, Atmos. Chem. Phys., 9, 831-848, doi:10.5194/acp-9-831-2009, 2009.

Theys, N., Van Roozendael, M., Hendrick, F., Yang, X., De Smedt, I., Richter, A., Begoin, M., Errera, Q., Johnston, P. V., Kreher, K., and De Mazière, M.: Global observations of tropospheric BrO columns using GOME-2 satellite data, Atmos. Chem. Phys., 11, 1791-1811, doi:10.5194/acp-11-1791-2011, 2011.

Toyota, K., McConnell, J. C., Lupu, A., Neary, L., McLinden, C. A., Richter, A., Kwok, R., Semeniuk, K., Kaminski, J. W., Gong, S.L., Jarosz, J., Chipperfield, M. P., and Sioris, C. E.: Analysis of reactive bromine production and ozone depletion in the Arctic boundary layer using 3-D simulations with GEM-AQ: inference from synoptic-scale patterns, Atmos. Chem. Phys., 11, 3949- 
3979, doi:10.5194/acp-11-3949-2011, 2011.

Tuckermann, M., Ackermann, R., Golz, C., Lorenzen-Schmidt, H., Senne, T., Stutz, J., Trost, B., Unold, W., and Platt, U.: DOASobservation of halogen radical-catalysed arctic boundary layer ozone destruction during the ARCTOC-campaigns 1995 and 1996 in Ny-Alesund, Spitsbergen, Tellus B, 49, 533-555, 1997.

Vandaele, A., Hermans, C., Simon, P., Carleer, M., Colin, R., and Fally, S.: Measurements of the $\mathrm{NO}_{2}$ absorption crosssection from $42000 \mathrm{~cm}^{-1}$ to $10000 \mathrm{~cm}^{-1}(238-1000 \mathrm{~nm})$ at $220 \mathrm{~K}$ and $294 \mathrm{~K}$, J. Quant. Spectrosc. Ra., 59, 171-184, doi:10.1016/S0022-4073(97)00168-4, 1998.

Vasilkov, A. P., Joiner, J., Haffner, D., Bhartia, P. K., and Spurr, R. J. D.: What do satellite backscatter ultraviolet and visible spectrometers see over snow and ice? A study of clouds and ozone using the A-train, Atmos. Meas. Tech., 3, 619-629, doi:10.5194/amt-3-619-2010, 2010.

Volkamer, R., Spietz, P., Burrows, J., and Platt, U.: Highresolution absorption cross-section of glyoxal in the UV-vis and IR spectral ranges, J. Photoch. Photobio. A, 172, 35-46, doi:10.1016/j.jphotochem.2004.11.011, 2005.

Wagner, T.: Satellite Observations of Atmospheric Halogen Oxides, $\mathrm{Ph} . \mathrm{D}$. thesis, University of Heidelberg, Mensch \& Buch Verlag, Berlin, 1999.

Wagner, T. and Platt, U.: Satellite mapping of enhanced $\mathrm{BrO}$ concentrations in the troposphere, Nature, 395, 486-490, doi:10.1038/26723, 1998.

Wagner, T., Leue, C., Wenig, M., Pfeilsticker, K., and Platt, U.: Spatial and temporal distribution of enhanced boundary layer $\mathrm{BrO}$ concentrations measured by the GOME instrument aboard ERS2, J. Geophys. Res., 106, 24225-24235, 2001.
Wagner, T., Ibrahim, O., Sinreich, R., Frieß, U., von Glasow, R., and Platt, U.: Enhanced tropospheric BrO over Antarctic sea ice in mid winter observed by MAX-DOAS on board the research vessel Polarstern, Atmos. Chem. Phys., 7, 3129-3142, doi:10.5194/acp-7-3129-2007, 2007.

Wagner, T., Beirle, S., and Deutschmann, T.: Three-dimensional simulation of the Ring effect in observations of scattered sun light using Monte Carlo radiative transfer models, Atmos. Meas. Tech., 2, 113-124, doi:10.5194/amt-2-113-2009, 2009a.

Wagner, T., Deutschmann, T., and Platt, U.: Determination of aerosol properties from MAX-DOAS observations of the Ring effect, Atmos. Meas. Tech., 2, 495-512, doi:10.5194/amt-2-4952009, 2009b.

Wang, P., Stammes, P., van der A, R., Pinardi, G., and Van Roozendael, M.: FRESCO+: an improved $\mathrm{O}_{2}$ A-band cloud retrieval algorithm for tropospheric trace gas retrievals, Atmos. Chem. Phys., 8, 6565-6576, doi:10.5194/acp-8-6565-2008, 2008.

Wilmouth, D., Hanisco, T., Donahue, N., and Anderson, J.: Fourier transform ultraviolet spectroscopy of the $\mathrm{A}^{2} \Pi_{(3 / 2)} \leftarrow$ $\mathrm{X}^{2} \Pi_{(3 / 2)}$ transition of BrO, J. Phys. Chem. A, 103, 8935-8945, doi:10.1021/jp991651o, 1999.

Winker, D. M., Hunt, W. H., and McGill, M. J.: Initial performance assessment of CALIOP, Geophys. Res. Lett., 34, L19803, doi:10.1029/2007GL030135, 2007. 